\title{
Espectroscopia e modelos atômicos: uma proposta para a discussão de con- ceitos de Física Moderna no ensino médio
}

\author{
Fábio Bartolomeu Santanal \\ Paulo José Sena dos Santos ${ }^{2}$ \\ Departamento de Física - Universidade Federal de Santa Catarina \\ Florianópolis - SC
}

\section{Resumo}

O texto apresenta os resultados da aplicação de uma sequência didática elaborada para a discussão de alguns conceitos de física moderna, a partir da questão: "como o homem sabe do que o Sol é feito se ele nunca esteve lá?". No percurso didático os conceitos relevantes - espectroscopia do século XIX, as quantizações da energia e da radiação, e os modelos atômicos propostos por Thomson, Rutherford e Bohr-foram abordados através do uso de: atividades experimentais, simulações, vídeos e da elaboração de textos e questões por parte dos estudantes. Neste trabalho serão apresentados os resultados de uma análise qualitativa de cinco questões da avaliação que abordaram os aspectos diretamente relacionados ao modelo de Bohr. Esta análise permitiu concluir que a sequência foi bem-sucedida, uma vez que mais de 50,0\% dos estudantes elaboraram respostas satisfatórias para as questões referentes às quantizações da energia e da radiação. Apesar do relativo sucesso percebeu-se que os estudantes apresentaram uma dificuldade em relacionar as transições eletrônicas com a formação dos espectros.

Palavras-chave: Espectros Contínuos e Discretos; Quantização da Energia; Modelo de Bohr.

\footnotetext{
+ Spectroscopy and atomic models: a proposal to teach Modern Physics at High School

* Recebido: novembro de 2016. Aceito: maio de 2017.

${ }^{1}$ E-mail: fabiobsantana74@gmail.com

2 E-mail: paulo.sena@ufsc.br
} 


\begin{abstract}
This text presents the results of a didactic sequence elaborated to discuss some modern Physics concepts. The sequence begins with the question: "how do we know the Sun's composition if we have never been there?". The teacher used experimental activities, simulations, texts and questions elaborated by students to discuss important concepts (spectroscopy, quantization of energy, and some atomic models). The qualitative analysis of five questions about Bohr's model will be presented. This analysis shows that more than $50 \%$ of students wrote good answers for the questions about quantization of energy and quantization of radiation. Although the sequence was successful, the students had difficulties to relate the electron's transitions with the rise of spectra.
\end{abstract}

Keywords: Continuous and Discrete Spectra; Quantization of Energy; Bohr's Model.

\title{
I. Introdução
}

A necessidade de abordagem da Física Moderna (FM) no Ensino Médio (EM) é consenso entre os pesquisadores (TERRAZAN, 1992; OLIVEIRA; VIANNA; GERBASSI, 2007). Revisões bibliográficas (PEREIRA; OSTERMANN, 2009; SILVA; ALMEIDA, 2011; REZENDE JR; CRUZ, 2009) indicam que os esforços investidos nessa temática têm crescido nos últimos anos, tanto para justificá-la quanto para compreendê-la e viabilizá-la. Apesar dos estudos citados apontarem relativa escassez, anais de eventos como Simpósio Nacional de Ensino de Física (SNEF), Encontro Nacional de Pesquisa em Ensino de Ciências (ENPEC) e Encontro de Pesquisa em Ensino de Física (EPEF) indicam diversos esforços para a mudança deste quadro.

Frente a este cenário foi proposta e aplicada uma sequência didática (SD) sobre os primeiros modelos atômicos em turmas do segundo ano do EM. Em sua elaboração procurouse evidenciar o uso de modelos para a construção do conhecimento científico, uma vez que tal abordagem está em sincronia com as necessidades apontadas pelas pesquisas em ensino de Física e os documentos oficiais para o ensino de ciências no ensino médio, tais como os Parâmetros Curriculares Nacionais (BRASIL, 2000), as Orientações Curriculares (BRASIL, 2006) e as Diretrizes Curriculares Nacionais para a Educação Básica (BRASIL, 2013).

A construção da SD foi norteada pela escolha de uma questão desencadeadora, apresentada aos estudantes no primeiro encontro: "Como o homem sabe do que o Sol é feito se ele nunca esteve lá?’. Para responder a esta questão, tomou-se a espectroscopia do século XIX 
como ponto de partida. Foi utilizada uma atividade experimental buscando evidenciar os espectros de emissão contínuos e discretos, e a necessidade da construção de modelos científicos para a constituição da matéria capazes de descrever os resultados obtidos a partir do século XIX.

Deste modo, a SD permitiu discutir os modelos atômicos propostos por Thomson, $\mathrm{Ru}-$ therford e Bohr, além de outros conceitos de FM, como a radiação de corpo negro e o efeito fotoelétrico. A proposta aqui apresentada foi composta por treze aulas divididas em dois blocos. No primeiro (aulas 1 a 7), foi abordada a espectroscopia desenvolvida no século XIX. No segundo (aulas 8 a 13) foram abordados os modelos e conceitos citados. Ao término de cada bloco foi realizada uma avaliação escrita.

Neste trabalho, será apresentada uma breve exposição referente à elaboração da SD, onde descrevemos cada uma das treze aulas que a compõem. Na sequência apresentamos as dificuldades apontadas por McKagan, Perkins e Wieman (2008) e Ivanjek et al (2015a, 2015b), relacionadas ao ensino e aprendizagem do modelo atômico de Bohr e dos espectros discretos, respectivamente. A seguir, será discutida a análise das respostas dos estudantes para um conjunto de questões referentes à segunda avaliação, as quais estão diretamente relacionadas ao modelo atômico de Bohr e seu uso na explicação das linhas espectrais. Por fim, serão apresentadas considerações finais.

\section{Percurso didático: conexões entre o desenvolvimento da espectroscopia e o nascimento da Física Moderna}

O estudo da espectroscopia desempenhou papel de destaque na evolução do conhecimento científico, primeiramente sobre a natureza da luz e o estudo das cores e em seguida na identificação de elementos químicos (FILGUEIRAS, 1996).

O fenômeno da decomposição da luz foi inicialmente descrito por I. Newton no século $\mathrm{XVII}$, identificando as cores do espectro visível em sua famosa experiência com um prisma. $\mathrm{O}$ astrônomo inglês W. Herschel, por volta de 1800, identificou uma radiação invisível no espectro da luz solar, próxima à região do vermelho, a qual foi denominada de infravermelho. Em 1801 o cientista alemão J. W. Ritter e o cientista inglês W. H. Wollaston descobriram no espectro da luz solar uma radiação mais energética além da faixa do violeta, a qual foi denominada ultravioleta.

Os trabalhos de W. H. Wollaston conduziram a descoberta de lacunas no espectro da luz solar, as quais se tornavam perceptíveis pela passagem da luz por uma pequena fenda, da ordem de 0,01 mm. O estudo destas linhas escuras foi ampliado por um construtor de instrumentos ópticos, o alemão J. Fraunhofer. Por volta de 1814 ele já havia identificado mais e 500 linhas escuras no espectro da luz solar. Além disso, ele identificou diferentes conjuntos de linhas escuras para diferentes estrelas e seus trabalhos também evidenciaram pela primeira vez a emissão de espectros discretos, resultantes da passagem de luz por um prisma, oriunda de diferentes materiais incandescentes. 
O estudo dos espectros luminosos teve um grande avanço com a invenção do espectroscópio por R. W. Bunsen e G. R. Kirchhoff em 1859. Este dispositivo e as leis da espectroscopia enunciadas por Kirchhoff permitiram o desenvolvimento de uma técnica eficaz para a identificação de elementos químicos através dos espectros produzidos.

O avanço da técnica permitiu ainda no século XIX a identificação de elementos químicos no Sol. É importante comentar que a análise direta do espectro solar apresentava dificuldades devido ao excesso de luz (ofuscamento). Isso implicava em analisar uma porção de luz, que ao emergir do interior do Sol, interage com as camadas gasosas externas, e produz um espectro de absorção. Diante desse problema, os eclipses propiciavam situações de observação mais apropriadas, uma vez que com o bloqueio do excesso de luz, captava-se a luz proveniente do disco solar, que era formada pelas erupções de gases das camadas interiores do Sol. Assim, em 1868, P. Janssen identificou vários elementos presentes nas camadas do Sol, e verificou que o hidrogênio é o mais abundante. Ao empregar novas técnicas que permitiram a análise das protuberâncias solares J. N. Lockyer identificou uma linha amarela no espectro das protuberâncias solares, mas não coincidente com o espectro de nenhum elemento conhecido. Ele concluiu que a sua origem era devido a um elemento químico ainda não encontrado na Terra, que ele chamou hélio (em homenagem ao deus grego). Esse elemento foi identificado aqui na Terra em 1895 por W. Ramsay.

O interesse no entendimento da emissão da radiação pelos corpos aquecidos foi iniciado por Kirchhoff devido a sua relação com a primeira lei da espectroscopia, que estabelece que todo corpo sólido aquecido apresenta um espectro contínuo de emissão. Ainda em 1859, ele mostrou que a razão entre a taxa de emissão e a taxa de absorção de radiação para um dado comprimento de onda a uma dada temperatura é a mesma para todos os corpos. Posteriormente, ele introduziu a noção de corpo perfeitamente negro, como aquele que apresenta a capacidade de absorver toda a radiação incidente sobre ele (STUDART, 2000).

Para um corpo negro ideal, a potência emissiva é uma função exclusiva da frequência da radiação e da temperatura na qual é emitida. A versão mais próxima de um corpo negro ideal consistia em um corpo inteiramente revestido com um material refletor, com uma pequena abertura por onde a radiação possa entrar e ser absorvida completamente pelo sistema. A pequena fração da energia que sai pelo orifício era o objeto da análise experimental. Portanto, o problema tornou-se a análise do comportamento da radiação de uma cavidade aquecida.

A busca pela descrição da radiação de corpo negro envolveu o trabalho conjunto entre físicos teóricos e experimentais e, ao final do século XIX, a determinação teórica da forma funcional para a distribuição das frequências emitidas e suas respectivas intensidades a uma dada temperatura era um dos maiores problemas da física teórica, uma vez que o emprego do eletromagnetismo e da termodinâmica não eram capazes de solucionar o problema.

Ao final do século XIX e início do século XX existiam várias propostas para a distribuição espectral da radiação de corpo negro, todas elas relativamente bem fundamentadas, porém os experimentos eram de difícil realização. Tecnicamente, as medidas de intensidade de 
radiação, emitidas por corpos aquecidos, ficavam restritas a uma determinada faixa de comprimentos de onda. A partir de 1896 o grupo de físicos experimentais liderados por O. Lummer e seus colaboradores, E. Pringsheim, H. Rubens e F. Kurlbaum, iniciaram os trabalhos para aferição das radiações de cavidade.

Em 1897, M. Planck iniciou seus estudos referentes à radiação de corpo negro com uma abordagem que envolveu a teoria eletromagnética e a segunda lei da termodinâmica. Ele propôs modelar as paredes da cavidade como constituídas por pequenos osciladores (os ressonadores). Este tratamento conduziu a uma concepção estatística discreta para a absorção de radiação pelos elementos constituintes da matéria.

No ano de 1900, Lord Rayleight (J. W. Strutt) publicou um resultado referente à distribuição espectral da radiação de corpo negro empregando o teorema da equipartição da energia. Devido às contribuições do físico J. Jeans, em 1905, a lei de distribuição proposta por Rayleigh passou a ser conhecida como lei de Rayleigh-Jeans.

Embora a lei de Rayleigh-Jeans se adequasse satisfatoriamente aos dados experimentais para baixas frequências, a fórmula falhava na região das altas frequências, uma vez que conduzia a valores infinitos para a intensidade emitida nesta faixa, fato este que ficou conhecido como a catástrofe do ultravioleta.

Em dezembro de 1900, Planck publicou um trabalho completo onde apresentou uma dedução teórica de sua fórmula para a distribuição espectral da radiação de corpo negro. Ele utilizou as ideias de Boltzmann sobre entropia e probabilidade, e introduziu a hipótese da descontinuidade da energia trocada pelos ressonadores. Esta hipótese resultou na quantização da energia, a qual não despertou nenhuma atenção da comunidade científica pelos 4 anos seguintes, uma vez que o próprio Planck permaneceu descontente com suas ideias relacionadas a quantização.

Em 1905, A. Einstein publicou um trabalho onde utilizou a hipótese da quantização da radiação eletromagnética na interpretação de alguns fenômenos relacionados com a absorção da luz por metais, dentre eles o efeito fotoelétrico. Esse fenômeno, observado inicialmente por Hertz em 1887 e muito estudado por Lenard em 1902, consiste na liberação de elétrons pela superfície de um metal após a absorção de energia da radiação eletromagnética incidente.

De acordo com Einstein, ao incidir no metal um quantum de luz (mais tarde denominado fóton) pode interagir com um elétron. Porém, para que este elétron seja liberado do metal, é necessário que ele adquira uma quantidade de energia, denominada função trabalho. Assim, eles serão liberados somente se os fótons tiverem uma energia maior que um valor mínimo. Deste modo, ele conseguiu obter uma equação para a explicação do fenômeno. Em 1914, R. A. Millikan, mesmo sem acreditar na validade da hipótese de Einstein para os quanta de luz, realizou experimentos que validaram essa equação e a utilizou na determinação precisa da constante de Planck (NIAZ et al, 2010).

Concomitantemente, outros cientistas trabalhavam em outros problemas relacionados a constituição da matéria. Ao final do século XIX, os trabalhos de J. J. Thomson com os raios 
catódicos forneceram dados que lhe permitiram conceber um modelo para o átomo. Segundo este modelo, o átomo seria uma esfera com uma distribuição uniforme de carga positiva, com portadores negativos de carga em movimento em seu interior. As concepções de Thomson acerca de um modelo para o átomo foram se modificando com o tempo, a ponto de obter uma constituição entre cargas positivas e negativas estável (THOMSON, 1904; LOPES; MARTINS, 2009). Além do modelo, Thomson foi capaz de estimar a razão entre a carga e a massa dos portadores negativos de carga (mais tarde denominados elétrons) e, em 1909, Millikan determinou a carga destas partículas.

Por volta de 1909, sob a supervisão de E. Rutherford, H. Geiger e E. Marsden realizaram um experimento com o intuito de investigar a estrutura do átomo pelo bombardeio de uma fina folha de ouro com partículas alfa. Em 1911 Rutherford publicou sua interpretação para os resultados deste experimento. Segundo Rutherford, os resultados indicavam que, ao contrário do modelo proposto por Thomson, a carga positiva deveria estar concentrada em uma região diminuta, denominada núcleo. Rutherford propôs, então, um modelo atômico no qual os elétrons estariam orbitando em torno de um núcleo positivo (RUTHERFORD, 1911).

Contudo, neste modelo, o átomo não poderia ser estável, pois elétrons em movimento em torno do núcleo, emitiriam radiação continuamente, e cairiam rapidamente sobre o núcleo. Neste contexto N. Bohr propõe seu modelo atômico para o átomo de hidrogênio.

O modelo proposto por Bohr estava baseado em alguns pressupostos clássicos, mas também incorporava hipóteses não asseguradas por quaisquer teorias clássicas à sua época (BOHR, 1913). Para descrever o átomo de hidrogênio, ele postulou que um elétron somente pode ocupar determinadas órbitas, portanto pode possuir somente determinados valores de energia, e que uma vez nestas órbitas não emite radiação. Ou seja, o comportamento de um elétron nestas órbitas não é descrito pela teoria eletromagnética clássica. Ainda segundo o modelo, um elétron pode passar de um nível permitido para outro. Para isso ele deve emitir ou absorver um fóton, cuja energia deve corresponder exatamente à diferença entre os níveis considerados. Dessa forma, quando um elétron absorve um fóton ele passa de um nível de energia inferior para um superior, já quando ele emite um fóton passa de um nível superior para um inferior.

Através desse mecanismo de emissão e absorção de fótons pelo elétron, o modelo foi capaz de descrever os espectros de emissão e absorção do hidrogênio (séries de Balmer, Paschen, Lyman e Pfund), justificou as diferenças entre os espectros de diferentes elementos químicos, decorrente das diferentes distribuições energéticas para diferentes átomos. Além disso, incorporou as hipóteses de Planck (quantização da energia) e de Einstein (quantização da radiação eletromagnética - fóton).

Devido aos postulados, o modelo foi recebido com certa resistência pela comunidade científica. Somente por volta de 1913, ele foi amplamente discutido na $83^{\text {a }}$ Reunião da Associação Britânica para o Progresso da Ciência (PINHEIRO; COSTA; MOREIRA, 2012). 
Apesar de fornecer alguns resultados consistentes somente para o átomo de hidrogênio, ele torna-se um modelo interessante para a discussão no ensino médio, devido a simplicidade matemática e a incorporação das ideias de quantização.

\section{II.1 Dificuldades apontadas pela literatura na abordagem dos espectros discretos e no modelo atômico de N. Bohr}

A pesquisa conduzida por Ivanjek et al. (2015a) realizada com estudantes de física americanos e croatas, em diversas fases do ensino superior, aponta, a partir da categorização das respostas a questões sobre linhas espectrais, que estes apresentam dificuldades de relacionar o mecanismo de emissão e absorção com a formação de espectros discretos, mesmo após discussões sobre o tema.

Segundo os pesquisadores o equívoco mais frequente, cometido por aproximadamente $50 \%$ dos estudantes, consiste em relacionar cada linha espectral com apenas um nível de energia, ao invés de relacioná-la com a transição do elétron entre dois níveis.

O estudo também mostrou que cerca de $50 \%$ dos estudantes conseguiram determinar o número total de transições possíveis em um átomo hipotético de quatro níveis. Desse total, apenas $15 \%$ foram capazes de explicar a emissão de fótons através da transição dos elétrons entre os níveis de energia. Eles também observaram que $10 \%$ dos estudantes tendem a considerar que os elétrons em um determinado nível de energia decaem diretamente para o estado fundamental, desconsiderando as possíveis transições de energia entre os estados intermediários.

A partir das dificuldades encontradas os autores elaboraram um tutorial para uma abordagem diferenciada sobre o tema (IVANJEK et al., 2015b). Esta proposta tem como objetivo principal que os estudantes estabeleçam relações entre as linhas espectrais e as transições dos elétrons entre dois níveis de energia. Os autores, após a aplicação de pré e pós-testes, afirmam que o uso do tutorial foi bem-sucedido.

Defende-se neste trabalho que para o entendimento de diversos aspectos conceituais associados ao fenômeno torna-se importante a discussão da necessidade das ideias da quantização da energia e da luz, e de alguns modelos para o átomo, especialmente o proposto por Bohr, que por sua importância histórica e simplicidade pode ser utilizado no ensino médio.

Mckagan, Perkins e Wieman (2008) também apontam dificuldades encontradas pelos estudantes de ensino superior no entendimento dos modelos atômicos. Os autores também compartilham a ideia de que o ensino do modelo de Bohr é um passo necessário ao entendimento de modelos atômicos que o sucederam, ao contrário de outros pesquisadores que defendem a ideia de que a abordagem deste modelo deveria ser evitada por supostamente implicar em obstáculos ao entendimento de um modelo quântico para o átomo. Um argumento favorável ao ensino do modelo de N. Bohr sustenta-se na ideia de que o confronto entre diferentes modelos permite discutir o papel do emprego de modelos na construção do conhecimento científico. 
No contexto da investigação proposta neste texto, os modelos atômicos estão presentes no currículo do EM, mais precisamente na disciplina de Química, e dessa forma é possível que os estudantes já disponham de algum conhecimento prévio sobre átomos. Em suas pesquisas, Mckagan, Perkins e Wieman (2008) apontam que as dificuldades encontradas pelos estudantes no ensino superior foram amenizadas pelo emprego de recursos metodológicos diversificados, como atividades em sala e tarefas de casa (ambas realizadas em grupos) e o uso de simulações. Outra estratégia didática empregada foi a discussão da evolução histórica dos modelos atômicos, enfatizando os avanços propiciados a cada novo modelo e as suas limitações frente ao modelo que o sucedeu.

Estes aspectos foram considerados nesta SD através da discussão dos avanços e limitações propiciados pelos modelos propostos por Thomson, Rutherford frente ao proposto por Bohr. Além disso, a SD proposta contemplou o emprego de abordagens metodológicas diversificadas, como as discussões e atividades em grupos. No que diz respeito ao uso de simulações, buscamos inseri-las com certa cautela, no sentido de que o seu emprego foi feito de forma expositiva e deste modo, optou-se pelo uso das simulações como recurso metodológico restrito ao professor. Nas ocasiões em que foram utilizadas procurou-se, contudo, enfatizar alguns aspectos dos modelos incorporados as simulações e as limitações decorrentes destes aspectos, tais como escalas de tamanho, atribuição de formas aos objetos quânticos, como os fótons, os elétrons, as órbitas eletrônicas, os modelos atômicos e o comportamento destes objetos nas simulações, uma vez que pesquisas apontam que os pressupostos levados em conta na construção das simulações, bem como as percepções que os estudantes tem delas pode refletir diretamente no aprendizado, tanto de forma positiva quanto de forma negativa (MEDEIROS; MEDEIROS, 2002).

Ainda segundo Mckagan, Perkins e Wieman (2008), os estudantes apresentaram dificuldades em compreender a importância da interpretação de Rutherford para o experimento de Geiger e Marsden, bem como a maneira como esta interpretação levou ao questionamento do modelo proposto por Thomson. Atentos a estas dificuldades procurou-se enfatizar algumas propriedades dos raios catódicos através de vídeos ilustrativos sobre a ampola de Crookes com o objetivo de discutir a maneira pela qual este experimento contribuiu para a descoberta das partículas negativas e suas propriedades, assim como as implicações destas descobertas na elaboração do modelo proposto por Thomson. Para a discussão do comportamento das partículas alfa no espalhamento de Rutherford, assim como a fragilidade do modelo de J. J. Thomson frente a estes novos resultados, optou-se pelo emprego de uma simulação para o experimento de $\mathrm{Ru}$ therford.

Para contrapor esses diferentes modelos novamente foi utilizada uma simulação que permitisse a discussão e a ênfase dos aspectos que levaram ao modelo proposto por Bohr a superar os que o precederam. 


\section{II.2 Sequência didática}

Nesta seção será apresentada uma síntese das atividades realizadas, além de seus objetivos e recursos empregados. As aulas tiveram 50 minutos de duração.

Aula 1 - O que são as estrelas? Por que nos importamos com elas?

Objetivos específicos: Caracterizar a composição das estrelas como conhecimento decisivo e indispensável para formulação de teorias cosmológicas e da constituição dos elementos químicos na tabela periódica; Discutir a importância do Sol como fonte de energia para a Terra; Caracterizar a energia recebida pela Terra oriunda do Sol;

Recursos instrucionais: Quadro, giz, vídeo 01 (série ABC da Astronomia ep. 6 - Estrelas, disponível em: $<h t t p: / / w w w . y o u t u b e . c o m / w a t c h ? v=o A V s z r K t 4 T w>$, acesso em 06/08/16).

A primeira aula foi destinada a introduzir a discussão inicial sobre as estrelas, em especial o Sol, com ênfase no papel por elas desempenhado na síntese de elementos químicos. Também foi discutida a influência e relevância do Sol em relação a vários processos ocorridos na Terra. Na parte final a questão desencadeadora foi apresentada: "como sabemos do que o Sol é feito se o homem nunca esteve lá?” Os estudantes, organizados em grupos, deveriam pesquisar e trazer na aula seguinte a resposta para a questão apresentada.

Aula 2 - Como sabemos do que o Sol é feito se o homem nunca foi até lá?

Objetivos específicos: Problematizar a obtenção de informações a partir da análise da luz oriunda do Sol; Discutir qualitativamente como o espectrômetro permite analisar a luz a partir do espectro das cores; Estabelecer a espectrometria como atividade científica dentro de um determinado contexto histórico;

Recursos instrucionais: Quadro e giz.

Os grupos apresentaram os resultados de suas pesquisas e os pontos mais importantes levantados pelos grupos foram anotados para discussão. Após as discussões iniciais sobre as repostas obtidas pelos grupos o encaminhamento da aula foi direcionado a discussão do papel da espectroscopia na astronomia, assim como funcionamento do espectroscópio, enfatizando o fenômeno da difração, pois este fenômeno está diretamente relacionado com a construção do espectroscópio de baixo custo, empregado pelos estudantes na atividade experimental programada para a aula 6 .

Aula 3 - O código das cores.

Objetivos específicos: Evidenciar os principais cientistas que contribuíram com o estabelecimento da espectroscopia como atividade de investigação científica; Evidenciar os espectros de emissão e absorção; 
Recursos instrucionais: Quadro, giz, Texto (Breve histórico da espectroscopia).

Nesta aula os estudantes organizados em grupos e munidos de um texto sobre a história da espectroscopia ${ }^{3}$, deveriam elaborar 10 questões com as respectivas respostas. As questões deveriam contemplar os pontos do texto que os grupos julgassem mais importantes. Ao término da aula os estudantes entregaram a atividade para o professor.

Aula 4 - Afinal, o que é a espectroscopia?

Objetivos específicos: Caracterizar o estabelecimento da espectroscopia como uma atividade de investigação científica; Caracterizar as contribuições de Isaac Newton, Willian Wollaston e Joseph Fraunhofer; Caracterizar as contribuições de Robert Wilhelm Bunsen e Gustav Robert Kirchhoff para a espectroscopia; Discutir e caracterizar as leis da espectroscopia estabelecidas por Gustav Robert Kirchhoff; Evidenciar o caráter classificatório das substâncias proporcionado pela análise espectroscópica das linhas de emissão e absorção;

Recursos instrucionais: Quadro, giz, Texto (Breve histórico da espectroscopia)

As questões elaboradas pelos grupos na aula anterior foram analisadas pelo professor. A partir de uma seleção, as questões que permitiriam encaminhar os objetivos da quarta aula foram apresentadas para discussão, inclusive com as respostas elaboradas pelos grupos. $\mathrm{O}$ objetivo desta aula foi aprofundar as discussões sobre a espectroscopia do século XIX, seu emprego, os avanços científicos que ela propiciou e os problemas que ela suscitou.

Aula 5 - Qual é a cor de uma lâmpada?

Objetivos específicos: Evidenciar a emissão de espectro contínuo por sólidos aquecidos; Evidenciar a emissão de espectros discretos por gases em alta pressão; Caracterizar os espectros, contínuo e descontínuo, de uma lâmpada de filamento e de lâmpadas de vapor sódio e de mercúrio, respectivamente;

Recursos instrucionais: Quadro, giz, Kit experimental 01, Roteiro de atividade experimental 01.

Foi realizada uma atividade investigativa com um kit experimental de baixo custo $^{4}$ (CAVALCANTE; TAVOLARO; HAAG, 2005). O aparato experimental permitiu aos estudantes visualizar os espectros de emissão de três fontes luminosas (lâmpada incandescente; lâmpada de vapor de sódio; lâmpada de vapor de mercúrio) empregando espectroscópios de baixo custo, construídos por eles mesmos.

As lâmpadas foram acesas individualmente e em cada observação os estudantes deveriam comparar o que era observado ao olharem diretamente para a fonte com o que era visto ao

\footnotetext{
${ }^{3} \mathrm{O}$ texto foi elaborado pelo professor e se encontra na íntegra junto à sequência didática, disponível em: $<$ http://repositorio.ufsc.br/handle/123456789/159352>.

${ }^{4} \mathrm{O}$ roteiro da atividade experimental e as instruções para elaboração do kit experimental estão disponíveis junto à sequência didática.
} 
olharem através do espectroscópio. Os grupos fizeram registros dos espectros observados (Fig. 1) através do espectroscópio, destacando as cores observadas e caracterizando-os como contínuos ou discretos.

Aula 6 - Análise do código das cores.

Objetivos específicos: Caracterizar as diferenças e semelhanças entre o espectro contínuo e o espectro descontínuo; Caracterizar o espectro de emissão de luz visível para um gás à alta pressão; Evidenciar a emissão de radiação infravermelha;

Recursos instrucionais: Quadro, giz, Kit experimental 01, Roteiro de atividade experimental 01.

$\mathrm{Na}$ aula, os estudantes voltaram a trabalhar em grupos na segunda parte do roteiro de atividades (o kit experimental foi novamente utilizado). De posse das imagens registradas na aula anterior (aula 5) os estudantes foram estimulados a evidenciarem as diferenças entre os espectros discretos e contínuos. Além disso, os estudantes verificaram que os espectros discretos das lâmpadas de vapor de sódio e mercúrio apresentavam um conjunto de cores diferentes. Para cada um dos espectros foi feita a correlação com uma das leis da espectroscopia.

As questões do roteiro de atividades também abordaram a interação da pele com a radiação infravermelha, a qual os estudantes puderam constatar pela sensação de calor ao aproximarem-se da lâmpada incandescente.
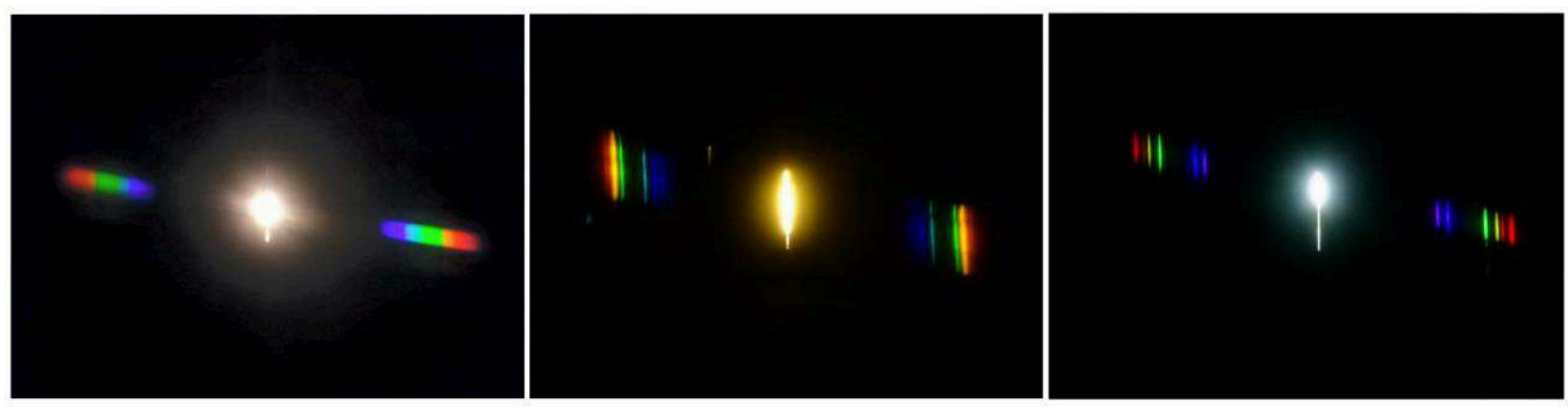

Fig. 1 -Espectros de emissão para as lâmpadas de filamento, vapor de sódio e vapor de mercúrio, respectivamente, obtido pelos estudantes a partir do uso dos espectroscópios de baixo custo. Fonte: Elaborado pelos autores.

Aula 7 - Hipóteses sobre a emissão de luz.

Objetivos específicos: Problematizar a emissão de espectros discretos; Caracterizar as cores de um objeto quando iluminado por uma fonte de luz; Discutir a influência da densidade do gás no espectro de emissão; Levantar hipóteses sobre a emissão de espectros discretos;

Recursos instrucionais: Quadro, giz, Roteiro de atividade experimental 01, simulação Phet Colorado (Visão e Cor), simulação Phet Colorado (Blackbody-spectrum). 
Os grupos retomaram o roteiro de atividades e as questões referentes à caracterização dos espectros foram brevemente discutidas, conjuntamente com o emprego, pelo professor, de duas simulações do projeto Phet Colorado como recurso didático auxiliar ${ }^{5}$.

Na sequência os estudantes iniciaram as atividades referentes à última parte do roteiro, composta por um conjunto de três questões, as quais estimularam os estudantes a levantarem hipóteses para a formação de espectros, contínuos na lâmpada de filamento incandescente, e discretos nas lâmpadas de vapor de sódio e mercúrio, assim como para as diferentes composições dos espectros discretos, como evidenciado pela atividade experimental para as lâmpadas de vapor de sódio e vapor de mercúrio.

Esta aula foi elaborada para realizar o fechamento do primeiro bloco de aulas, referente à espectroscopia do século XIX. A última questão do roteiro de atividades oportunizou a apresentação da questão desencadeadora do segundo bloco de aulas: "porque as linhas do espectro do sódio diferem das linhas do espectro de mercúrio?". Esta questão foi proposta com dois objetivos. O primeiro foi resgatar o uso das técnicas da espectroscopia como meio de identificação dos elementos químicos. O segundo e principal objetivo foi discutir a necessidade de um modelo atômico capaz de descrever os espectros de emissão discretos e específicos para cada elemento químico.

Aula 8 - A natureza íntima da matéria se revela.

Objetivos específicos: Caracterizar o contexto teórico-experimental do início do século XX que influenciou a elaboração dos modelos atômicos de J. J. Thomson e E. Rutherford; Discutir o papel das evidências experimentais que influenciaram os modelos de J. J. Thomson e E. Rutherford; Evidenciar as fragilidades dos modelos de J. J. Thomson e E. Rutherford;

Recursos instrucionais: Quadro, giz, texto 02, tarefa sugerida.

Durante a aula foi caracterizado o contexto teórico experimental envolvido na formulação dos modelos atômicos de Thomson e Rutherford. Os estudantes receberam um texto para leitura $^{6}$, no qual foram apresentados alguns fatos históricos referentes a algumas descobertas experimentais que corroboraram com o atomismo e levaram a elaboração dos modelos atômicos do final do século XIX e início do século XX.

Duas atividades foram vinculadas ao texto. A primeira foi realizada no decorrer da aula, onde os estudantes, organizados em grupos de quatro a cinco componentes, deveriam formular cinco questões (com suas respectivas respostas) sobre os pontos do texto que julgassem mais importantes. A segunda atividade foi realizada individualmente, como tarefa para casa.

\footnotetext{
5 Visão e Cor, disponível em: <https://phet.colorado.edu/pt_BR/simulation/legacy/color-vision>, acesso em: 05 ago. 2016; Blackbody-spectrum, disponível em: <https://phet.colorado.edu/pt_BR/simulation/legacy/blackbodyspectrum>, acesso em: 05 ago. 2016.

${ }^{6} \mathrm{O}$ texto foi elaborado pelo professor e está disponível, na íntegra, junto à sequência didática.
} 
Nesta atividade, os estudantes deveriam responder a um conjunto de sete questões elaboradas pelo professor e entregá-las por meio de formulário eletrônico. Esta atividade foi analisada pelo professor antes da realização da aula seguinte, como forma de antecipar os pontos em que os estudantes apresentaram maiores dificuldades.

Aula 9 - Hipóteses sobre a natureza íntima da matéria.

Objetivos específicos: Analisar e discutir o experimento de J. J. Thomson com os raios catódicos; Analisar e discutir o experimento de Geiger-Marsden; Analisar e discutir a interpretação de E. Rutherford para o experimento de Geiger-Marsden;

Recursos instrucionais: Quadro, giz, vídeo 03 (Modelos atômicos - Thomson), vídeo 04 (Raios catódicos), vídeo 05 (Modelos atômicos - Rutherford), simulação Phet Colorado (Espalhamento de Rutherford).

A aula foi iniciada com uma breve discussão das questões elaboradas pelos estudantes no encontro anterior. A seguir discutiu-se os experimentos de Thomson e Geiger e Marsden (espalhamento de Rutherford).

Foram apresentados dois vídeos de curta duração, um sobre J. J. Thomson e seus experimentos com o tubo de Crookes $^{7}$ e outro reproduzindo as propriedades dos raios catódicos ${ }^{8}$.

Um terceiro vídeo ${ }^{9}$ abordou brevemente o experimento de Geiger-Marsden e a interpretação dada por Rutherford para os resultados deste experimento. Por fim foi empregada, pelo professor, uma simulação do projeto Phet Colorado ${ }^{10}$ para comparar os modelos atômicos de Thomson e Rutherford.

Aula 10 - Max Planck e o nascimento da mecânica quântica.

Objetivos específicos: Contextualizar a hipótese da quantização da energia; Caracterizar o corpo negro (irradiador ideal); Caracterizar a discrepância entre as previsões da física clássica e os resultados experimentais para o fenômeno da radiação de corpo negro; Apresentar a hipótese da quantização da energia de Max Planck para descrever a radiação de corpo negro;

Recursos instrucionais: Quadro, giz, simulação Nebraska Astronomy Applet Project (Melted Nail Demonstration), vídeo 06 (Induction Heater melting and boiling copper).

$\mathrm{Na}$ aula foram apresentadas as dificuldades encontradas pelos cientistas na descrição do fenômeno da radiação de corpo negro. Inicialmente foi enfatizada a idealização necessária à

\footnotetext{
${ }^{7}$ Disponível em: <https://www.youtube.com/watch?v=i9xMrNDHWts>. Acesso em: 06 ago. 2016.

${ }^{8}$ Disponível em: <https://www.youtube.com/watch?v=81gflafhDp4>. Acesso em: 06 ago. 2016.

${ }^{9}$ Disponível em: <https://www.youtube.com/watch?v=HRmdkAAoZ5M>. Acesso em: 06 ago. 2016.

${ }^{10}$ Disponível em: <https://phet.colorado.edu/pt_BR/simulation/legacy/rutherford-scattering>. Acesso em: 06 ago. 2016.
} 
descrição do fenômeno, caracterizando o corpo negro na situação de equilíbrio termodinâmico, como emissor e absorvedor ideal.

É importante salientar que a profundidade matemática e conceitual inerentes ao fenômeno em questão foi evitada. O objetivo pretendido foi somente apresentar a hipótese de $\mathrm{M}$. Planck referente à quantização da energia e a consequente ruptura com os conceitos clássicos, para ilustrar o surgimento da FM.

Foi realizado um breve contraponto entre algumas das previsões das teorias clássicas, como a termodinâmica e do eletromagnetismo, frente aos dados experimentais. Neste contexto a hipótese de M. Planck foi apresentada como uma tentativa de conciliar os dados experimentais a uma descrição matemática, e que tal hipótese abria mão da absorção contínua de energia, tal como previsto pelas teorias clássicas, para assumir a hipótese de absorção de energia de maneira discreta.

O grande impacto causado pelas ideias propostas por Planck foi brevemente abordado. Na sequência uma simulação ${ }^{11}$ foi utilizada pelo professor para ilustrar o comportamento da curva de emissão de um corpo aquecido, assim como foi apresentado um vídeo ${ }^{12}$ em que um pequeno pedaço de metal era aquecido até tornar-se incandescente para ilustrar o fenômeno da emissão de radiação pelos corpos aquecidos.

Aula 11 - Albert Einstein e os quanta de luz.

Objetivos específicos: Contextualizar a hipótese dos quanta de luz; Caracterizar a discrepância entre as previsões da física clássica e os resultados experimentais sobre o efeito fotoelétrico; Apresentar a hipótese de Albert Einstein para descrever o efeito fotoelétrico;

Recursos instrucionais: Quadro, giz, simulação Phet Colorado (Efeito Fotoelétrico) e texto 03.

Esta aula foi dedicada a apresentação e discussão da hipótese dos quanta de luz de Einstein. Foi brevemente explanado sobre a controvérsia científica existente na virada do século XIX para o século XX com respeito a descrição do fenômeno da emissão de cargas elétricas por superfícies metálicas desencadeada pela incidência de luz, a partir de uma breve descrição qualitativa do fenômeno.

Optou-se por não apresentar as várias hipóteses para descrição do fenômeno vigentes à época. Foi apenas mencionado que existiam várias hipóteses para descrição do fenômeno. Para uma mínima compreensão da controvérsia científica, enfatizou-se que além de existirem várias hipóteses, nenhuma delas era capaz de elucidar o fenômeno, no sentido de obter uma descrição matemática e conceitual através do eletromagnetismo clássico.

Foram relacionados alguns aspectos intrigantes do fenômeno, tais como a discrepância entre o tempo necessário e o previsto para a energia ser absorvida pelas cargas, a inesperada

\footnotetext{
${ }^{11}$ Disponível em: <http://astro.unl.edu/classaction/animations/light/meltednail.html>. Acesso em: 06 ago. 2016.

12 Disponível em: <https://www.youtube.com/watch?v=zw_SrGU2iYs>. Acesso em: 06 ago. 2016.
} 
relação entre a energia cinética das cargas ejetadas e a frequência da radiação incidente e o vínculo, teoricamente inexistente, entre a intensidade da luz incidente com a quantidade de cargas ejetadas.

Uma simulação ${ }^{13}$ foi empregada pelo professor para ilustrar os aspectos acima mencionados. Por fim, a hipótese dos quanta de luz proposta por Einstein foi brevemente apresentada, enfatizando que a mesma causou impacto diante da comunidade científica de maneira similar a hipótese de Planck. Novamente neste ponto deve-se enfatizar que o enfoque dado foi voltado para a discussão de aspectos voltados para a natureza do conhecimento científico.

O conceito de quantum de luz e a equação de Einstein para a energia do fóton foram apresentados e discutidos, isso possibilitou mencionar sucintamente a dualidade onda-partícula para a luz.

Ao término da aula os estudantes receberam um texto de apoio ${ }^{14}$ que abordou os aspectos históricos como: a espectroscopia e suas contribuições, os problemas teóricos da Física Clássica da virada do século XIX para o século XX, a Radiação de Corpo Negro e o Efeito Fotoelétrico. Por fim, o texto antecipou as implicações que estes avanços tiveram sobre os trabalhos de Bohr e seu modelo atômico inovador.

A partir do texto os estudantes receberam uma tarefa para casa, a ser concluída individualmente e que consistiu em responder a um conjunto de questões relacionadas ao texto. As respostas foram registradas em um formulário on-line.

Aula 12 - A quantização da energia e o modelo atômico de Bohr.

Objetivos específicos: Caracterizar o quadro teórico-experimental da primeira década do século XX frente aos fenômenos da radiação de corpo negro, o efeito fotoelétrico, o modelo de J. J. Thomson para o átomo, o modelo de Rutherford e os resultados da espectroscopia; Caracterizar o modelo atômico de Bohr para o átomo de hidrogênio; Caracterizar a emissão e absorção de radiação pelo átomo segundo o modelo de Bohr para o átomo de hidrogênio.

Recursos instrucionais: Quadro, giz, simulação NAAP (Hydrogen Atom Simulator).

Nesta aula o objetivo foi caracterizar o átomo de Bohr, através da indicação de alguns de seus postulados e da ênfase em seu caráter semiclássico. Dessa forma, primeiramente foram retomados os modelos atômicos de Thomson e Rutherford, e as hipóteses lançadas por Planck e Einstein, sobre a quantização da energia e dos quanta de luz, respectivamente.

A questão da instabilidade do modelo atômico de Rutherford foi brevemente descrita para estabelecer uma conexão entre a quantização das órbitas, introduzida por Bohr como forma de resolver o problema da estabilidade do átomo. A partir deste ponto foi discutido o mecanismo de emissão e absorção de energia, com ênfase na maneira pela qual as hipóteses da quantização

\footnotetext{
${ }^{13}$ Disponível em <https://phet.colorado.edu/pt_BR/simulation/legacy/photoelectric>. Acesso em: 06 ago. 2016.

${ }^{14} \mathrm{O}$ texto foi elaborado pelo professor e está disponível, na íntegra, junto à sequência didática.
} 
de energia e dos quanta de luz foram incorporadas ao modelo atômico para o átomo de hidrogênio. $\mathrm{O}$ emprego de termos como energia cinética e órbitas circulares foram brevemente discutidos de maneira a evidenciar que apesar das hipóteses inovadores introduzidas por Bohr, seu modelo ainda apresentava aspectos da Física Clássica.

Foram empregadas algumas imagens para melhor ilustrar alguns aspectos relacionados ao entendimento das radiações. Primeiramente foi apresentada uma imagem do espectro eletromagnético (Fig. 2-a). A referida imagem foi projetada em uma tela e as faixas do infravermelho, visível e ultravioleta foram destacadas, resgatando a atividade experimental realizada com o espectroscópio, enfatizando o aspecto contínuo do espectro observado para um sólido aquecido. As demais faixas de radiações foram brevemente comentadas, ressaltando a frequência e o comprimento de onda como elementos que as caracterizam, assim como a relação da frequência com a energia dos fótons. Uma outra imagem foi empregada para ilustrar como interpreta-se a absorção e emissão de luz no modelo proposto por Bohr (Fig. 2-b). A partir desta imagem foi discutida a absorção de um fóton correspondente ao comprimento de onda de 6563 angstrons (vermelho) por um elétron, causando sua transição do nível de energia $\mathrm{N}=2$ para o nível de energia $\mathrm{N}=3$, indicando que esta transição corresponde a uma linha de absorção (linha escura no espectro contínuo). Na mesma imagem foi também ilustrado o processo de emissão de um fóton, quando o elétron transita do nível de energia $\mathrm{N}=3$ para o nível de energia $\mathrm{N}=2$, produzindo então uma linha brilhante (espectro de emissão discreto).
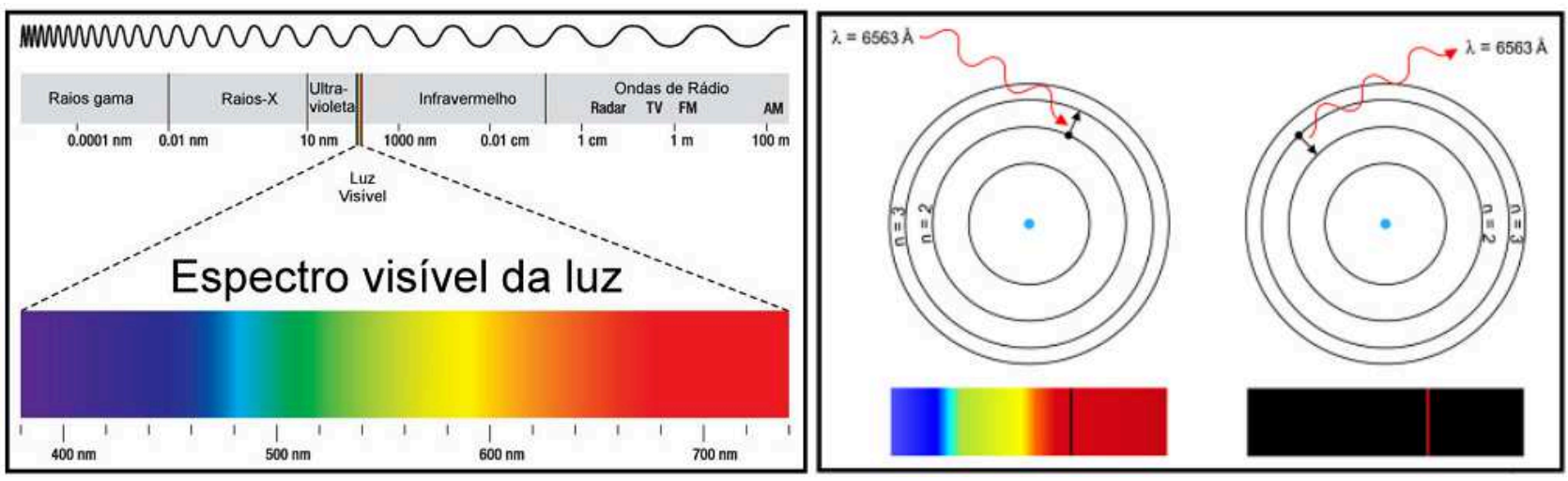

Fig. 2 - Espectro eletromagnético (a) e mecanismo de emissão e absorção de fótons pelo átomo (b), respectivamente. Fonte: Disponíveis em: (a) <http://www.infoescola.com/fisica/espectro-eletromagnetico/>, e (b) <http://www.if.ufrgs.br/fis02001/aulas/aula_espec. htm >. Acesso em: 07 ago. 2016.

As séries de emissão para o átomo de hidrogênio, estabelecidas por Balmer, Paschen e Lyman a partir das técnicas da espectroscopia foram apresentadas a partir de uma imagem com os seis primeiros níveis de energia para o átomo de hidrogênio (Fig. 3-a), com ênfase em seu caráter discreto, assim como a relação entre a energia dos fótons e a diferença entre a energia das órbitas permitidas envolvidas na referida transição e indicando, neste caso, o emprego da 
equação de Einstein para a energia do fóton. Foi destacado que as linhas correspondentes a série de Lyman implicam em transições eletrônicas dos níveis superiores para o estado fundamental $(\mathrm{N}=1)$, de modo que as energias associadas a estas transições estão relacionadas a emissão de radiação na faixa do ultravioleta. No caso da série de Balmer, foi enfatizado que as transições ocorrem dos níveis superiores para o estado de energia com $\mathrm{N}=2$, nas quais as energias envolvidas estão associadas a fótons na faixa visível do espectro, se relacionado, portanto, as faixas coloridas do espectro de emissão. A série de Paschen corresponde as transições eletrônicas e ocorrem dos níveis superiores para o estado de energia com $\mathrm{N}=3$, estando dessa forma associadas a emissão de fótons menos energéticos, propriamente aqueles na faixa do infravermelho. Em seguida as linhas de emissão da série de Balmer para o átomo de hidrogênio foram ilustradas (Fig. 3-b), associando as energias de cada transição com a frequência da cor para cada uma das linhas observadas na referida figura.
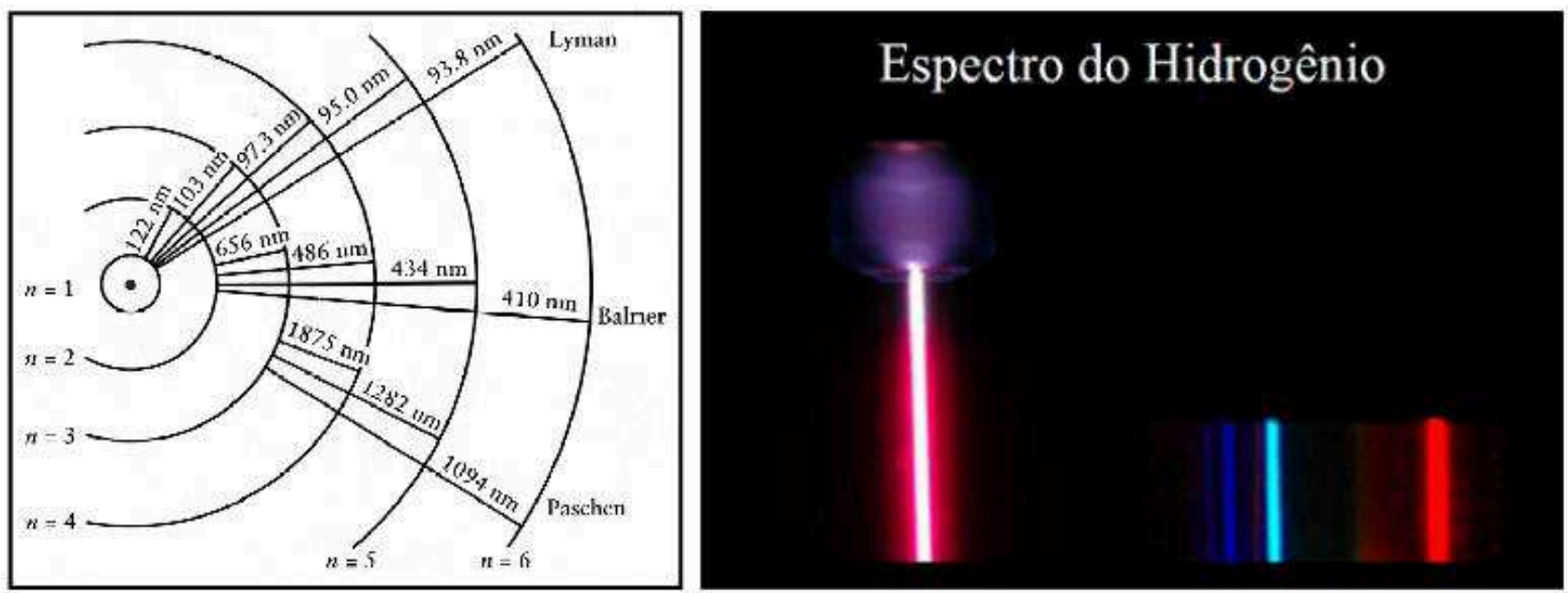

Fig. 3 - Séries da Balmer, Lyman e Paschen (a) e espectro de emissão visível para o átomo de hidrogênio (b). Fonte: Disponíveis em: (a) <http://crab0.astr.nthu.edu.tw/ hchang/gal/f0503-H_Trans.JPG>e (b) <http://slideplayer.com.br/slide/46897/>. Acesso em: 08 ago. 2016.

Para o fechamento da aula foi empregada uma simulação ${ }^{15}$ computacional referente ao mecanismo de emissão e absorção de energia no átomo de hidrogênio para todas as linhas das séries de Balmer, Lyman e Paschen, com discussão de seu caráter discreto da interação do fóton com o elétron, assim como da quantização da energia envolvida nas transições em decorrência das órbitas permitidas preestabelecidas para o elétron.

\footnotetext{
15 Disponível em: <http://astro.unl.edu/classaction/animations/light/hydrogenatom.html>. Acesso em: 06 ago. 2016.
} 
Aula 13 - Os saltos quânticos no átomo de hidrogênio.

Objetivos específicos: Caracterizar as transições eletrônicas no átomo de hidrogênio a partir da emissão e absorção de fótons; Evidenciar a relação entre a emissão de fótons com o espectro de emissão do átomo de hidrogênio; Relacionar a quantização das órbitas com o aspecto discreto do espectro de emissão do átomo de hidrogênio;

Recursos instrucionais: Quadro, giz, Roteiro de atividade prática de simulação 01, simulação Phet Colorado (Modelos do átomo de hidrogênio).

A última aula da sequência didática foi destinada à caracterização do átomo do hidrogênio segundo o modelo atômico de Bohr, com ênfase no mecanismo de absorção e emissão de fótons através de uma simulação ${ }^{16}$.

Um roteiro foi elaborado para que os estudantes utilizassem a simulação no laboratório de informática da unidade escolar. Contudo, problemas técnicos inviabilizaram a atividade. Em virtude deste problema a simulação foi utilizada pelo professor de maneira expositiva.

O ponto de partida foi a apresentação da equação para os níveis de energia do átomo de hidrogênio. Pelo emprego desta equação os estudantes calcularam a energia para as seis primeiras órbitas permitidas para o elétron. Na sequência foram listadas todas as possíveis transições entre os seis primeiros níveis de energia e a energia envolvida em cada uma das transições. As energias necessárias em cada transição foram discutidas, comparadas e relacionadas com as séries de Balmer, Lyman e Paschen.

Após as discussões inicias a simulação foi acionada em uma lousa digital. Os vários recursos disponíveis na simulação foram explorados. O emprego da simulação permitiu discutir vários aspectos relacionados ao modelo atômico proposto por Bohr, suscitando, inclusive, discussões relacionadas ao aspecto probabilístico das transições de níveis superiores para níveis inferiores de energia.

O uso da simulação estimulou a realização de perguntas por parte dos estudantes. Diante desta circunstância o uso da simulação foi priorizado e a resolução da parte final do roteiro foi encaminhada para que os estudantes resolvessem em casa. Na aula seguinte os estudantes puderam esclarecer as dúvidas relacionadas com a parte final do roteiro.

\section{Metodologia}

Antes de iniciar a aplicação da SD foi encaminhado um Termo de Consentimento Livre e Esclarecido aos pais dando ciência do trabalho a ser realizado e dos dados a serem coletados. A SD foi aplicada em duas turmas do segundo ano do ensino médio de uma escola privada situada no município de São José (Grande Florianópolis). Os estudantes realizaram várias

\footnotetext{
16 Disponível em: <https://phet.colorado.edu/pt_BR/simulation/legacy/hydrogen-atom>. Acesso em: 06 ago. 2016.
} 
atividades avaliativas que nos permitiram coletar dados em diferentes formatos. Todas as aulas foram registradas em áudio e a produção textual realizada foi coletada através de formulários eletrônicos ou digitalizada.

Além destas atividades foram propostas duas avaliações escritas e individuais. A primeira contemplou as discussões realizadas entre as aulas 1 a 7 sobre a espectroscopia do século XIX. A segunda ocorreu ao término da SD e foi referente as aulas 8 a 13. Essa avaliação, composta por 11 questões, foi realizada por 61 estudantes em uma aula de 50 minutos. Eles puderam consultar os textos e as anotações feitas durante as aulas.

Para a investigação do entendimento dos aspectos diretamente relacionados ao uso do modelo de Bohr para formulações de explicações sobre os espectros atômicos foram analisadas cinco questões (denominadas daqui por diante primeira, segunda, terceira, quarta e quinta questões) diretamente relacionadas ao tema. Neste processo utilizamos uma abordagem qualitativa, que se justifica pois permite ao pesquisador entender "a forma como as pessoas constroem o mundo a sua volta, o que estão fazendo, ou o que está lhes acontecendo (...)" (FLICK, 2009, p.8). Na construção desse entendimento procuramos identificar a maneira como os estudantes articularam os conceitos que consideramos relevantes nas suas respostas para as questões. Assim, as respostas para as três primeiras questões foram categorizadas em cinco grupos:

- Grupo 1: repostas que articularam corretamente os conceitos de FM necessários para responder adequadamente a referida questão.

- Grupo 2: respostas que articularam corretamente alguns dos conceitos de FM necessários para responder adequadamente a referida questão.

- Grupo 3: respostas que articulam corretamente conceitos de FM tratados ao longo da $\mathrm{SD}$, mas que não estavam diretamente relacionados com a referida questão.

- Grupo 4: respostas que não articularam adequadamente nenhum dos conceitos de FM tratados ao longo da sequência didática.

- Grupo 5: respostas deixadas em branco.

Para a quarta e quinta questões os grupos de categorização foram definidos especificamente e estão descritos junto à análise destas questões. Na discussão de cada uma das questões indicamos os critérios específicos para cada grupo de categorização e ilustramos dois exemplos de respostas elaboradas pelos estudantes. Finalmente, apresentamos em um quadro a quantidade de respostas presentes em cada grupo, assim como o percentual que elas representam em relação ao total de respostas para a referida questão.

Na próxima seção serão apresentados os enunciados dessas questões, os conceitos que consideramos fundamentais nas respostas, e exemplos sobre a categorização. É importante salientar que a categorização por nós empregada não tem relação com os critérios de correção empregados na avaliação. 


\section{Análise das respostas dos estudantes}

\section{IV.1 Primeira questão}

A primeira questão analisada apresentou o enunciado: "O maior desafio de N. Bohr era estabilizar o modelo atômico proposto por E. Rutherford. Para tanto, utilizou as ideias de M. Planck, ou seja, N. Bohr utilizou as ideias da quantização em seu modelo atômico. Qual foi a característica do átomo que foi quantizada por N. Bohr. ”.

O objetivo desta questão foi verificar se os estudantes compreenderam de que maneira a hipótese de Planck foi incorporada por Bohr em seu modelo atômico. Esperava-se que os estudantes relacionassem os conceitos de quantização de energia com aspectos como a quantização das órbitas ou quantização dos níveis de energia.

As respostas categorizadas no Grupo 1 empregaram termos como "quantização das órbitas", "quantização de níveis de energia", "órbitas permitidas" e "quantização de energia trocada pelo elétron" com a articulação destes conceitos com aspectos do modelo atômico de Bohr. São exemplos de respostas neste grupo: "Quantização da energia do átomo (quantizar órbitas). Os elétrons se distribuem em órbitas bem determinadas e estáveis. "; "A energia que o elétron precisa para 'trocar de nível'.".

As respostas categorizadas no Grupo 2 mencionaram a estabilidade das órbitas sem relacionar com a emissão de radiação, saltos quânticos ou com a diferença de energia entre os níveis da transição. São exemplos de respostas neste grupo: "A descrição de Bohr sobre o átomo considera que o elétron gira em torno do núcleo em órbitas. Órbitas são estáveis."; "Que o elétron gira em torno do núcleo em órbitas bem determinadas.".

As respostas categorizadas no Grupo 3 mencionaram corretamente alguns conceitos de FM, sem articular estes conceitos com o modelo atômico de Bohr, como solicitado pela questão. São exemplos de respostas neste grupo: "Que a matéria troca energia de forma discreta, isso é, a energia apresenta quantidade mínima e é trocada em quantidades bem definidas"; "Solucionou o problema da instabilidade do átomo e ajustou com notável simplicidade a descontinuidade dos espectros".

As respostas categorizadas no Grupo 4 não contém conceitos de FM ou não apresentaram uma articulação adequada destes conceitos. São exemplos de respostas neste grupo: " $A$ carga elétrica. "; “A radiação de corpo negro.”. O Grupo 5 corresponde a quantidade de respostas deixadas em branco. A distribuição estatística das respostas frente aos grupos de categorização considerados para a referida questão é apresentada no Quadro 1.

Quadro 1 - Quantidade de respostas por grupo de categorização referente a análise da primeira questão.

\begin{tabular}{ccccc}
\hline Grupo 1 & Grupo 2 & Grupo 3 & Grupo 4 & Grupo 5 \\
\hline $24(39,3 \%)$ & $14(23,0 \%)$ & $11(18,0 \%)$ & $9(14,8 \%)$ & $3(4,9 \%)$ \\
\hline
\end{tabular}


A quantidade de respostas categorizadas nos Grupos 1 e 2 indica que os estudantes apresentaram um bom entendimento sobre a forma como o modelo de Bohr incorporou a hipótese de Planck referente a quantização da energia.

Por outro lado, a análise das respostas categorizadas no Grupo 3 revelou que em 8 das 11 respostas há referências explícitas ao problema da radiação de corpo negro, possivelmente motivado pela menção a Planck no enunciado da questão. Embora não tenham feito a correlação com o modelo Bohr, nota-se que articularam corretamente alguns conceitos relacionados a radiação de corpo negro. Da mesma forma, em 3 das 11 respostas encontramos referência do problema da instabilidade do modelo de Rutherford, possivelmente também motivadas pelo enunciado da questão.

\section{IV.2 Segunda questão}

O enunciado da segunda questão foi: "Os estudos de A. Einstein sobre o efeito fotoelétrico também foram considerados por $N$. Bohr na elaboração de seu modelo atômico. De que maneira N. Bohr interpretava o mecanismo de emissão e absorção de luz pelo elétron no átomo de hidrogênio?".

Esta questão foi elaborada com o intuito de verificar se os estudantes compreenderam como as ideias de Einstein sobre a quantização da radiação foram incorporadas por Bohr ao seu modelo atômico. Esperava-se que os estudantes relacionassem o mecanismo de emissão ou absorção de luz pelo elétron a partir da emissão ou absorção de fótons, e a relação destes processos com os saltos quânticos do elétron entre os níveis de energia.

As respostas categorizadas no Grupo 1 articularam corretamente a interação do elétron com a radiação pela emissão ou absorção de fótons, correlacionando este processo com os saltos quânticos do elétron entre dois níveis de energia. São exemplos de respostas neste grupo: " $A o$ receber energia (fóton), o elétron pode "saltar" para níveis superiores absorvendo a luz, e após algum tempo o elétron decai espontaneamente para um nível inferior, emitindo um fóton de energia (luz).”; "Quando elétron aumentava de nível ele absorvia 1 fóton quando ele decaia de nível liberava um fóton.".

As respostas categorizadas no Grupo 2 mencionaram corretamente as mudanças entre níveis de energia pela absorção ou emissão de luz, mas não explicitaram o caráter corpuscular da luz, ou seja, não mencionaram o termo fóton ou termos que remetessem ao mesmo significado, como "pacote de energia" ou "quantum de radiação". São exemplos de respostas neste grupo: "O elétron pode "saltar" para níveis de energia mais elevados se absorver energia na forma de radiação, ou seja, se absorver luz."; “A absorção e a emissão de energia pelo elétron implica em mudanças de níveis."

As respostas categorizadas no Grupo 3 mencionaram corretamente alguns aspectos referentes ao modelo atômico de N. Bohr, mas sem articularem estes conceitos conforme solicitado no enunciado da questão. São exemplos de respostas neste grupo: “É que cada elemento 
emite apenas um conjunto de cores bem especifica."; "Bohr postulou que as órbitas são estáveis, ou seja, não há emissão de radiação pelos elétrons, como na teoria eletromagnética.".

As respostas categorizadas no Grupo 4 não contém conceitos de FM ou não apresentaram uma articulação adequada destes conceitos. São exemplos de repostas neste grupo: "Não há emissão de radiação pelo elétron, nem de absorção."; "Radiação de corpo negro e efeito fotoelétrico que deu a quantização da energia.". O Grupo 5 corresponde as respostas deixadas em branco. A distribuição estatística das respostas frente aos grupos de categorização considerados para a referida questão é apresentada no Quadro 2.

Quadro 2 - Quantidade de respostas por grupo de categorização referente a análise da segunda questão.

\begin{tabular}{ccccc}
\hline Grupo 1 & Grupo 2 & Grupo 3 & Grupo 4 & Grupo 5 \\
\hline $32(52,4 \%)$ & $15(24,6 \%)$ & $2(3,3 \%)$ & $3(4,9 \%)$ & $9(14,8 \%)$ \\
\hline
\end{tabular}

A quantidade de respostas categorizadas no Grupo 1 indica que os estudantes assimilaram satisfatoriamente a maneira como as ideias de Einstein referentes a quantização da luz foram incorporadas por Bohr ao seu modelo atômico. Além disso, a quantidade de respostas categorizadas no Grupo 2 evidencia que embora alguns estudantes não tenham explicitado a relação entre o conceito de fóton com o mecanismo de emissão e absorção de luz, ainda assim foram capazes de argumentar que a emissão e absorção de luz pelo átomo implica que os elétrons transitem entre diferentes níveis de energia.

Segundo IVANJEK et al (2015a), muitos estudantes de nível superior ${ }^{17}$ apresentam dificuldades em descrever os processos de emissão e absorção de fótons pelos elétrons e sua consequente relação com os saltos quânticos entre diferentes níveis de energia. Logo, chama a atenção o grande percentual das respostas categorizadas nos Grupos 1 e 2, assim como o seu nível de articulação.

\section{IV.3 Terceira questão}

A terceira questão apresentou o seguinte enunciado: "Até a época de N. Bohr não se sabia por que os espectros dos elementos químicos eram discretos. Além disso, o espectro dos elementos químicos era composto por um determinado conjunto de cores, diferente para cada elemento. Com o modelo atômico de N. Bohr foi possível explicar por que isto ocorre. Com base neste modelo, explique por que o espectro de emissão dos elementos químicos é discreto e não contínuo.".

17 Todos os estudantes assistidos pelas pesquisas de IVANJEK et al (2015a) eram acadêmicos do curso de Física em nível superior com formação voltada para licenciatura. Os estudantes pesquisados pertencem a vários níveis distintos, desde as fases iniciais até as fases mais avançadas da graduação. 
A referida questão foi elaborada com o objetivo de verificar se os estudantes assimilaram a maneira pela qual o modelo proposto por Bohr foi capaz de explicar os espectros discretos. Para esta questão esperava-se que os estudantes fossem capazes de correlacionar a emissão de espectros discretos com a quantização dos níveis de energia.

As respostas categorizadas no Grupo 1 apontaram que o espectro de emissão é discreto devido a diferença de energia entre os níveis serem bem definidos. São exemplos de repostas neste grupo: "Pois existem predeterminados níveis de energia para onde os elétrons podem ser excitados, e somente apresenta cores os que retornam ao nível 2, assim, a existência da quantização da energia faz com que os espectros sejam discretos."; "Pois os níveis de energia têm uma certa "distância" entre eles que faz com o espectro seja discreto.".

As respostas categorizadas no Grupo 2 mencionaram a emissão e/ou absorção de luz na transição entre os níveis de energia mas não mencionam a quantização dos níveis de energia, o que implica diretamente na emissão discreta. São exemplos de respostas neste grupo: "Pois ele recebe cargas de energia variada, podendo saltar para níveis de energia mais elevados e depois decair espontaneamente para um nivel de energia inferior."; "Porque os elétrons se distribuem em órbitas, e ao receber ou emitir energia, consequentemente muda de órbita.".

As respostas categorizadas no Grupo 3 mencionaram a emissão e/ou absorção de luz sem correlacionar tais processos explicitamente com a quantização de energia, ou com as diferentes distribuições eletrônicas dos diferentes elementos químicos. São exemplos de respostas neste grupo: "Pois provou que os átomos além de emitir cores, também tinham a capacidade de absorver, criando as linhas escuras e as linhas coloridas (incluindo UV e IV)."; "Porque se o elétron absorve o fóton depois ele terá que emiti-lo e isto libera pacote de luz.".

As respostas categorizadas no Grupo 4 não contém conceitos de FM ou não apresentaram uma articulação adequada destes conceitos. São exemplos de respostas neste grupo: "Pois alguns espectros apresentam partes que não podem ser vistas, tornando discretos."; "Porque apresenta linhas escuras que aparecem pois certos elementos químicos não são absorvidos.". O Grupo 5 corresponde as respostas deixadas em branco. A distribuição estatística das respostas frente aos grupos de categorização considerados para a referida questão apresentase no Quadro 3.

Quadro 3 - Quantidade de respostas por grupo de categorização referentes a análise da terceira questão.

\begin{tabular}{ccccc}
\hline Grupo 1 & Grupo 2 & Grupo 3 & Grupo 4 & Grupo 5 \\
\hline $10(16,4 \%)$ & $13(21,3 \%)$ & $10(16,4 \%)$ & $14(23,0 \%)$ & $14(23,0 \%)$ \\
\hline
\end{tabular}

A distribuição das respostas nos grupos de categorização sugere que esta questão foi de difícil compreensão pelos estudantes. Deve-se considerar que a elaboração para esta resposta exigiu uma articulação dos conceitos envolvidos na primeira e segunda questões. Dessa forma, 
é interessante analisar como os estudantes de cada um dos 5 grupos desta questão foi categorizado na primeira e segunda questões. O interesse nesta análise está no fato de que um bom entendimento da origem dos espectros e do modelo de Bohr passa por uma boa compreensão da quantização da energia e da quantização da radiação (BASSO, 2004; PEDUZZI; BASSO, 2005).

Ao analisar as respostas que os 10 estudantes do Grupo 1 elaboraram para a primeira e a segunda questões (Tabela 1) foi percebido que a maioria elaborou respostas muito satisfatórias.

Tabela 1 - Distribuição das respostas na primeira e na segunda questão, referentes ao grupo 1 da terceira questão.

\section{Terceira Questão - Grupo 1}

Categorização das respostas na primeira questão

\begin{tabular}{ccccc}
\hline Grupo 1 & Grupo 2 & Grupo 3 & Grupo 4 & Grupo 5 \\
7 & 2 & 1 & 0 & 0 \\
\hline \multicolumn{7}{c}{ Categorização das respostas na segunda questão } \\
\hline Grupo 1 & Grupo 2 & Grupo 3 & Grupo 4 & Grupo 5 \\
7 & 3 & 0 & 0 & 0 \\
\hline
\end{tabular}

Dos 10 estudantes, 7 tiveram suas respostas categorizadas no Grupo 1 da primeira questão, e o mesmo ocorreu para a segunda questão. Além disso, verifica-se que nenhum dos 10 estudantes elaborou respostas desarticuladas para essas questões.

Fato similar ocorreu com os estudantes do Grupo 2. A análise da distribuição das respostas (Tabela 2) deste grupo também indica que os 13 estudantes formularam boas respostas para a primeira e segunda questão.

Tabela 2 - Distribuição das respostas na primeira e na segunda questão, referentes ao grupo 2 da terceira questão.

Terceira Questão - Grupo 2

Categorização das respostas na primeira questão

\begin{tabular}{ccccc}
\hline Grupo 1 & Grupo 2 & Grupo 3 & Grupo 4 & Grupo 5 \\
5 & 3 & 3 & 2 & 0 \\
\hline Categorização das respostas na segunda questão & \\
\hline Grupo 1 & Grupo 2 & Grupo 3 & Grupo 4 & Grupo 5 \\
6 & 3 & 2 & 2 & 0 \\
\hline
\end{tabular}


Nota-se que neste grupo um número maior de estudantes teve suas respostas categorizadas nos Grupos 3 e 4, tanto na primeira quanto na segunda questão, ou seja, neste grupo, um número maior de estudantes apresentou dificuldades em compreender como as ideias da quantização da energia e/ou do quantum de luz estão presentes no modelo atômico de Bohr, refletindo diretamente na elaboração de suas respostas para a questão 3.

Por outro lado, a quantidade de respostas nos Grupos 1 e 2 da primeira e segunda questões indica que mesmo os estudantes que apresentaram domínio dos conceitos envolvidos com a quantização da energia e/ou com o quantum de luz apresentaram dificuldades em compreender a formação dos espectros discretos.

A análise da distribuição das respostas do Grupo 3 (Tabela 3) na primeira e segunda questões indicou outro aspecto relevante. Para este grupo de estudantes a dificuldade em compreender as ideias da quantização da energia ficou mais evidente na distribuição de suas respostas para a questão 1 , fato este não observado para a segunda questão.

Tabela 3 - Distribuição das respostas na primeira e na segunda questão, referentes ao grupo 3 da terceira questão.

\section{Terceira Questão - Grupo 3}

Categorização das respostas na primeira questão

\begin{tabular}{ccccc}
\hline Grupo 1 & Grupo 2 & Grupo 3 & Grupo 4 & Grupo 5 \\
3 & 3 & 1 & 2 & 1 \\
\hline Categorização das respostas na segunda questão & \\
\hline Grupo 1 & Grupo 2 & Grupo 3 & Grupo 4 & Grupo 5 \\
7 & 1 & 0 & 1 & 1 \\
\hline
\end{tabular}

Para as respostas categorizadas no Grupo 4 da terceira questão (Tabela 4) notamos que os estudantes desse grupo elaboraram respostas satisfatórias para a primeira e segunda questões. Contudo, neste grupo estão categorizadas as respostas sem uma correta articulação de conceitos de FM, ou seja, estes estudantes mostraram um domínio das ideias referentes à quantização da energia e do quantum de luz, mas não conseguiram articular estes conceitos de modo a construir uma explicação para a emissão dos espectros discretos com uso do modelo de Bohr. 
Tabela 4 - Distribuição das respostas na primeira e na segunda questão, referentes ao grupo 4 da terceira questão.

\begin{tabular}{|c|c|c|c|c|}
\hline \multicolumn{5}{|c|}{ Terceira Questão - Grupo 4} \\
\hline \multicolumn{5}{|c|}{ Categorização das respostas na primeira questão } \\
\hline Grupo 1 & Grupo 2 & Grupo 3 & Grupo 4 & Grupo 5 \\
\hline 6 & 3 & 4 & 1 & 0 \\
\hline \multicolumn{5}{|c|}{ Categorização das respostas na segunda questão } \\
\hline Grupo 1 & Grupo 2 & Grupo 3 & Grupo 4 & Grupo 5 \\
\hline 7 & 3 & 2 & 1 & 1 \\
\hline
\end{tabular}

A análise das respostas dos estudantes que deixaram a terceira questão em branco (Tabela 5) mostra outro aspecto importante. Chama a atenção o fato de que 8 dos 14 estudantes que deixaram a terceira questão em branco não compreenderam adequadamente as ideias da quantização da energia e 7 dentre estes 14 também deixaram em branco a segunda questão.

Tabela 5 - Distribuição das respostas na primeira e na segunda questão, referentes ao grupo 5 da terceira questão.

Terceira Questão - Grupo 5

\begin{tabular}{ccccc}
\hline \multicolumn{5}{c}{ Categorização das respostas na primeira questão } \\
\hline Grupo 1 & Grupo 2 & Grupo 3 & Grupo 4 & Grupo 5 \\
4 & 2 & 2 & 4 & 2 \\
\hline \multicolumn{7}{c}{ Categorização das respostas na segunda questão } & \\
\hline Grupo 1 & Grupo 2 & Grupo 3 & Grupo 4 & Grupo 5 \\
5 & 1 & 1 & 0 & 7 \\
\hline
\end{tabular}

A verificação de como os estudantes de cada um dos 5 grupos referentes a terceira questão elaborou suas respostas para a primeira e para a segunda questão evidenciou a importância do entendimento dos conceitos referentes a quantização da energia e a quantização da luz para o entendimento da emissão dos espectros discretos. Além disso, a inclusão destes conceitos na SD não garante por si só o entendimento acerca da emissão dos espectros discretos.

Ivanjek et al. (2015a) afirmam que os estudantes apresentam dificuldades em estabelecer relações entre o mecanismo de emissão e absorção com a formação dos espectros discretos. Porém após a aplicação de uma sequência didática (IVANJEK et al., 2015b), eles relatam uma melhora significativa neste ponto. Isso mostra a importância da elaboração das atividades no processo de ensino e aprendizagem. Deste modo, os resultados aqui apresentados sugerem alguns ajustes na SD aqui apresentada. $\mathrm{O}$ uso da simulação para o modelo de Bohr foi mais 
voltado para os aspectos das transições eletrônicas entre as órbitas. Uma maneira de melhorar o entendimento dos estudantes talvez seja o emprego da simulação também para discussão da relação entre as ideias da quantização da energia presentes na radiação de corpo negro e no efeito fotoelétrico com o modelo de Bohr. Além disso, a SD não contempla nenhuma atividade proposta objetivamente com a finalidade de enfatizar a discussão sobre estas ideias.

\section{IV.4 Quarta questão}

Antes de analisar a quarta questão, é interessante contextualizá-la na avaliação, uma vez que para esta questão foram concedidos dois recursos auxiliares. Um deles fornecia, no formato de tabela, a relação das linhas espectrais de emissão do átomo de hidrogênio, nas regiões do infravermelho, do visível e do ultravioleta indicando, inclusive, a energia dos fótons associados a cada linha espectral (Fig. 4-a). O outro recurso apresentava uma ilustração com os 6 primeiros níveis de energia do átomo de hidrogênio, onde era explicitamente indicado o número quântico principal de cada nível e a respectiva energia correspondente a cada um dos níveis (Fig. 4-b).

\begin{tabular}{|l|l|l|}
\hline $\begin{array}{l}\text { Faixa do espectro } \\
\text { (fóton) }\end{array}$ & Cor & $\begin{array}{l}\text { Energia do } \\
\text { fóton }\end{array}$ \\
\hline Infravermelho & --- & $0,66 \mathrm{eV}$ \\
\hline Infravermelho & --- & $0,97 \mathrm{eV}$ \\
\hline Infravermelho & --- & $1,13 \mathrm{eV}$ \\
\hline Visível & Vermelho & $1,89 \mathrm{eV}$ \\
\hline Visível & Ciano & $2,55 \mathrm{eV}$ \\
\hline Visível & Azul & $2,86 \mathrm{eV}$ \\
\hline Visível & Anil & $3,02 \mathrm{eV}$ \\
\hline Ultravioleta & --- & $10,20 \mathrm{eV}$ \\
\hline Ultravioleta & --- & $12,09 \mathrm{eV}$ \\
\hline Ultravioleta & --- & $12,75 \mathrm{eV}$ \\
\hline Ultravioleta & --- & $13,06 \mathrm{eV}$ \\
\hline Ultravioleta & --- & $13,22 \mathrm{eV}$ \\
\hline
\end{tabular}

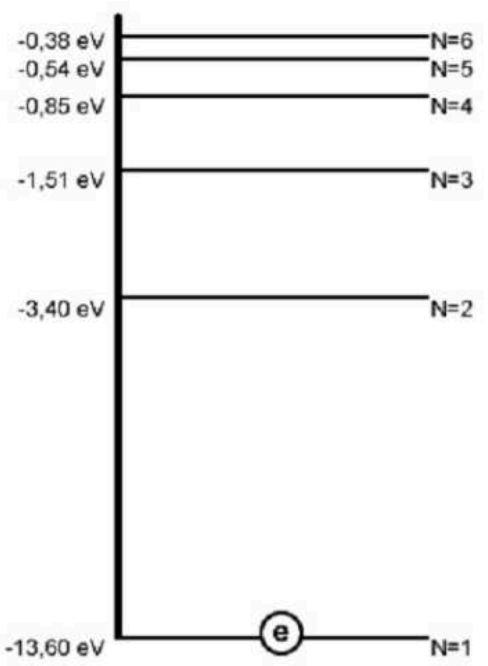

Fig. 4 - (a) À esquerda, tabela informativa de algumas faixas espectrais do átomo de hidrogênio; (b) à direita, ilustração dos seis primeiros níveis de energia do átomo de hidrogênio. Fonte: Elaborado pelos autores.

A quarta questão apresentou o seguinte enunciado: "Considere que o elétron esteja na órbita correspondente ao nível 4 de energia. Estando neste nível, relacione quais são as possíveis transições que o elétron pode sofrer ao decair até o estado fundamental.".

Esta questão teve por objetivo verificar se os estudantes seriam capazes de identificar as possíveis transições para um elétron no átomo de hidrogênio que, estando em um determinado nível de energia, sofresse decaimentos espontâneos até atingir o estado fundamental. De- 
veriam, portanto, enumerar as transições diretas para o estado fundamental, bem como as transições entre os níveis de energia intermediários, sendo estas, $4 \rightarrow 3,3 \rightarrow 2,3 \rightarrow 1,4 \rightarrow 2,2 \rightarrow 1$ e $4 \rightarrow 1$. As respostas foram categorizadas em 6 grupos.

As respostas categorizadas no Grupo 1 indicaram corretamente todas as 6 transições possíveis. São exemplos de respostas categorizadas neste grupo: "Do $4 \rightarrow 3$, do $3 \rightarrow 2$ e do $2 \rightarrow 1$ ou pode pular direto para $1(4 \rightarrow 1)$ ou para o $2(4 \rightarrow 2)$ e depois para o $1(2 \rightarrow 1)$."; "Pode cair para o nível 3, 2 ou 1. Se ele cair para o 3 pode ir até o 2 e 1. Caindo pro 2 pode decair somente pro $1 "$.

As respostas categorizadas no Grupo 2 identificaram de 3 a 5 das 6 transições possíveis. São exemplos de respostas categorizadas neste grupo: "O elétron pode ir do: $4 \rightarrow 3 \rightarrow 2 \rightarrow 1$, $4 \rightarrow 2 \rightarrow 1,4 \rightarrow 1$ ”; " $4 \rightarrow 1,4 \rightarrow 2,4 \rightarrow 3,4 \rightarrow 1$ (passando pelo 2 e 3 )”.

As respostas categorizadas no Grupo 3 identificaram especificamente as transições $4 \rightarrow 3,4 \rightarrow 2$ e $4 \rightarrow 1$. São exemplos de respostas categorizadas neste grupo: "Pode cair do $n=4$ para $n=3$, liberando infravermelho. De $n=4$ para $n=3$, liberando a cor ciano. De $n=4$ para $n=1$, emitindo ultravioleta."; "4 $\rightarrow 3,0,66 \mathrm{eV}$, infravermelho; $4 \rightarrow 2,2,55 \mathrm{eV}$, visivel; $4 \rightarrow 1$, $11,75 \mathrm{eV}$, ultravioleta.".

As respostas categorizadas no Grupo 4 relacionaram transições do nível 4 para algum nível superior $(4 \rightarrow 5,4 \rightarrow 6$ ), uma delas ou ambas, não identificando, necessariamente todas as demais transições possíveis do nível 4 para o nível 1. São exemplos de respostas categorizadas neste grupo: " $4 \rightarrow 5,4 \rightarrow 6$ para que o elétron sofra e decaia."; " $4 \rightarrow 5,4 \rightarrow 6,4 \rightarrow 3,4 \rightarrow 2,4 \rightarrow 1$ ".

As respostas categorizadas no Grupo 5 não continham nenhum elemento considerado relevante. São exemplos de respostas categorizadas neste grupo: "6 transições"; "estágios que pode sofrer ao decair até atingir o estado fundamental.". O Grupo 6 corresponde as respostas deixadas em branco. A distribuição estatística das respostas frente aos grupos de categorização considerados para a referida questão apresenta-se no Quadro 4.

Quadro 4 - Quantidade de respostas por grupo de categorização referentes a análise da quarta questão.

\begin{tabular}{cccccc}
\hline Grupo 1 & Grupo 2 & Grupo 3 & Grupo 4 & Grupo 5 & Grupo 6 \\
\hline $11(18,0 \%)$ & $6(9,8 \%)$ & $30(49,2 \%)$ & $10(16,4 \%)$ & $2(3,3 \%)$ & $2(3,3 \%)$ \\
\hline
\end{tabular}

No contexto aqui considerado, os Grupos 1 e 2 correspondem a um percentual de 28 $\%$ de respostas cuja elaboração descreveu total ou parcialmente os conhecimentos envolvidos para responder satisfatoriamente à questão. Além disso, o Grupo 3 (cerca de $49 \%$ ) foi capaz de identificar 3 das 6 transições possíveis.

A análise das respostas indica ainda que os processos de transição do elétron entre os níveis de energia necessitam ser aprofundados na sequência didática. Em tempo, deve-se registrar que tais processos foram previamente contemplados pelas atividades propostas, inclusive 
com características similares. A grande quantidade de respostas que listaram apenas as transições diretas do nível 4 para algum outro nível $(4 \rightarrow 3,4 \rightarrow 2$ e $4 \rightarrow 1)$ reforça a necessidade em explorar mais profundamente estes conceitos.

Segundo resultados obtidos por IVANJEK et al (2015a), estudantes de Física em nível superior, quando submetidos a uma questão de composição similar, apresentaram percentual de $55 \%$ de acerto. No referido trabalho a questão proposta aos estudantes fornecia apenas 4 níveis de energia, referentes a um átomo hipotético. Neste caso, portanto, não ocorre a possibilidade de haverem transições para estados de energia acima do nível 4.

\section{IV.5 Quinta questão}

A quinta questão teve como enunciado: A figura abaixo representa o espectro de emissão do átomo de hidrogênio na faixa do visível. As linhas coloridas correspondem a série de Balmer, assim denominada em homenagem ao Físico suíço Johann Jakob Balmer. A série de Balmer corresponde a todas as possíveis transições do elétron dos níveis 3, 4, 5 ou 6 para o nivel 2.

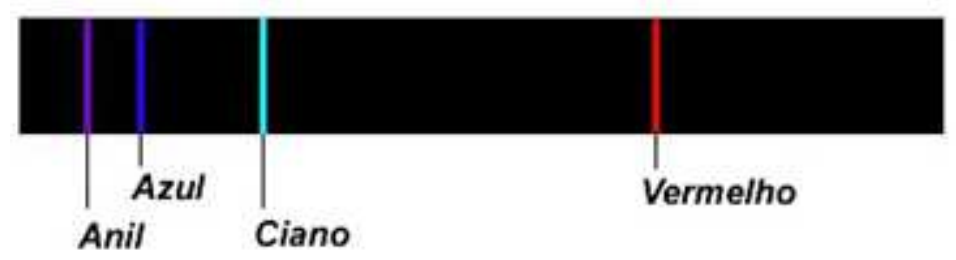

Fig. 5 - Linhas do espectro visível do átomo de hidrogênio. Fonte: Elabora pelos autores a partir de <http://blogdequimica2014.blogspot.com.br/2014/08/modelo-atomico-debohr.html>. Acesso em: 16 set. 2016.

Verifique na tabela (Fig. 4-a) a energia dos fótons correspondentes a cada uma das cores. A seguir identifique entre quais níveis de energia o elétron deve 'saltar' para emitir um fóton correspondente a cada uma das cores do espectro. Registre a sua resposta relacionando as transições em ordem crescente de frequência. Descreva, logo abaixo, como você foi capaz de identificar que a frequência de uma cor é maior que a das outras.

Esta questão teve por objetivo verificar se os estudantes seriam capazes de correlacionar as cores das linhas espectrais do átomo de hidrogênio com as respectivas transições do elétron entre níveis de energia característicos de cada linha espectral da série de Balmer. Além disso, os estudantes deveriam articular o uso da equação de Einstein para identificar a proporção direta entre a energia dos fótons com a frequência da luz a eles associada. Os recursos auxiliares disponibilizados para a quarta questão (Fig. 4) poderiam também ser empregados na resolução desta questão. Assim, os estudantes deveriam ordenar corretamente as cores emitidas por ordem 
de frequência, indicando os níveis de energia envolvidos em cada emissão e justificar o ordenamento pelo emprego da equação de Einstein para a energia do fóton, $E=h . f$. As respostas foram categorizadas em 5 grupos.

As respostas categorizadas no Grupo 1 correlacionaram corretamente cada uma das cores com a respectiva transição, especificando os níveis de energia envolvidos, ordenando corretamente em ordem crescente de energia e justificando o ordenamento a partir da relação de A. Einstein para a energia do fóton. São exemplos de respostas neste grupo: "Pode-se constatar isso pela maior diferença de eV entre os níveis. Assim, a transição $6 \rightarrow 2$ envolverá mais energia e terá uma frequência maior do que a $3 \rightarrow 2$."; "Quanto mais energético, a frequência é mais alta.".

As respostas categorizadas no Grupo 2 ordenaram e correlacionaram corretamente as transições, especificando os níveis de e energia envolvidos, mas não justificaram o ordenamento, ou seja, não fez o emprego da equação de A. Einstein para a energia do fóton. Seguem algumas respostas categorizadas neste grupo: "Pois libera mais energia."; "É possível saber por meio da energia emitida em cada transição. ”.

As respostas categorizadas no Grupo 3 relacionaram as transições em ordem inversa aquela estipulada pelo enunciado da questão, algumas justificadas e outras sem justificativa. Seguem alguns exemplos de respostas categorizadas neste grupo: "Pela energia associada ao fóton."; "Pois neste caso a luz foi tomado como onda, tendo assim, comprimento e frequência, e a diferença de frequência resulta em cores diferentes.".

As respostas categorizadas no Grupo 4 relacionaram algumas das linhas e/ou apresentaram alguma justificativa sem elementos considerados relevantes. São exemplos de respostas neste grupo: "Através da altura da pilha, que é a intensidade ou brilho."; "O azul tem menos fótons que os outros e o ciano têm mais fótons. ”. Nestas respostas notamos o emprego de elementos textuais decorrentes do uso da simulação. A expressão "altura da pilha" é um exemplo disso, o qual se refere ao empilhamento dos fótons emitidos pelo átomo, disponibilizada pela simulação em determina parte da tela (Fig. 6), bem como a associação direta entre esta imagem e aquela disponibilizada na avaliação (Fig. 5). Este aspecto chama atenção para a necessidade de estar atento às diversas interpretações que os estudantes podem elaborar ao terem contato com as simulações.

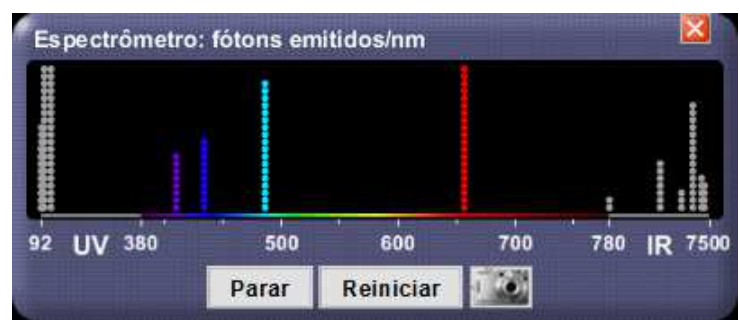

Fig. 6 - Quadro disponibilizado pela simulação para indicar a quantidade de fótons emitidos nas transições eletrônicas. Fonte: disponível em <https://phet.colorado.edu/ pt_BR/simulation/legacy/hydrogen-atom>. Acesso em: 16 set. 2016. 
O Grupo 5 corresponde as respostas deixadas em branco. A distribuição estatística das respostas frente aos grupos de categorização considerados apresenta-se no Quadro 5.

Quadro 5 - Quantidade de respostas por grupo de categorização referentes a análise da quinta questão.

\begin{tabular}{ccccc}
\hline Grupo 1 & Grupo 2 & Grupo 3 & Grupo 4 & Grupo 5 \\
\hline $15(24,6 \%)$ & $16(26,2 \%)$ & $10(16,4 \%)$ & $10(16,4 \%)$ & $10(16,4 \%)$ \\
\hline
\end{tabular}

A quantidade de respostas bem elaboradas (grupos 1 e 2) e satisfatórias (grupo 3) parecem indicar que a relação entre energia e frequência para o fóton foi devidamente enfatizada pela SD. Entretanto, um aspecto chamou a atenção, sendo observado nos Grupos 2, 3, 4 e 5. Vários estudantes não compreenderam a diferença entre transições do tipo $3 \rightarrow 2$ e $2 \rightarrow 3$, pois não fizeram distinção entre a notação que representa os processos de emissão e absorção. $\mathrm{Na}$ Fig. 7, ilustramos um exemplo do emprego equivocado desta notação.

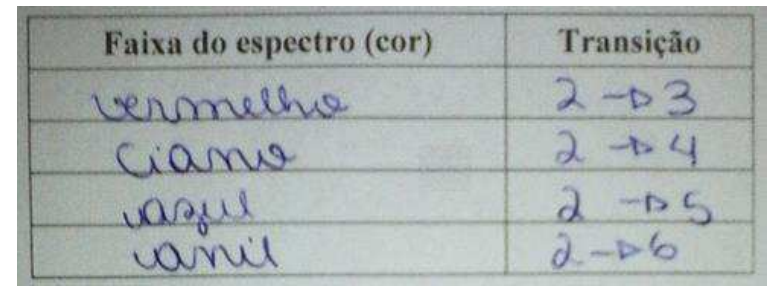

Fig. 7 - Emprego equivocado da notação para os processos de emissão de radiação decorrente das transições eletrônicas no átomo de hidrogênio. Fonte: Elaborado pelos autores a partir do acervo da pesquisa.

Diversas respostas fizeram referência as transições do nível 2 para outros níveis superiores, as quais dizem respeito aos processos de absorção e não de emissão. Assim, embora o uso desta notação tenha sido empregado no decorrer das aulas onde estes conceitos forma tratados, parece ser necessário que este aspecto deva ser enfatizado, evidenciando a diferença entre os processos de emissão e absorção.

\section{Considerações finais}

Neste trabalho procuramos contribuir com a discussão acerca da inserção dos conceitos de FM no EM, através da elaboração e aplicação uma sequência didática.

O ponto de partida foi a questão: "como o homem sabe do que o Sol é feito se ele nunca esteve por lá?". Para a obtenção da resposta foram necessárias discussões sobre as descobertas propiciadas pelo avanço das técnicas de espectroscopia ao longo do século XIX, a necessidade do desenvolvimento de uma nova física que permitiu o entendimento da estrutura 
da matéria, e o papel dos modelos na construção do conhecimento científico. Também, foram utilizadas diversas abordagens, como: atividades experimentais, produção de textos, atividades de elaboração de questões, além do uso de vídeos e simulações.

Podemos considerar que com relação ao entendimento sobre as quantizações da energia e da radiação, a sequência foi bem-sucedida, uma vez que 62,3\% e 73,0\% das respostas dos estudantes para a primeira e segunda questões foram categorizadas nos grupos 1 e 2, ou seja, elas apresentaram uma boa articulação dos conceitos considerados importantes.

A terceira questão apresentou um índice menor de respostas bem articuladas (pertencentes aos grupos 1 e 2) 37,7\%. Uma análise mais aprofundada indica que os estudantes destes grupos, de maneira geral, apresentaram também respostas bem articuladas para a primeira e segunda questões. Isso é um indicativo da necessidade de um bom entendimento tanto da quantização da energia, quanto da quantização da radiação, para um bom entendimento do modelo de Bohr. Esse fato também foi apontado por Basso (2004) e Peduzzi e Basso (2005), ao afirmar que para o ensino do átomo de Bohr em nível médio os professores devem considerar conceitos e teorias que contextualizem o assunto e evidenciem as insuficiências dos modelos clássicos no estudo do átomo, como a radiação do corpo negro e o efeito fotoelétrico. Isso mostra a importância da inserção de mais atividades que façam a articulação entre esses conceitos. Devido a abstração destes fenômenos, uma alternativa poderia ser a elaboração de atividades envolvendo o uso de simulações (WIEMAN et al., 2008).

Os alunos também apresentaram dificuldades no entendimento do processo de transição de um elétron entre os níveis de energia, contemplado na quarta questão, uma vez que 27,8\% dos estudantes elaboraram respostas bem articuladas (grupos 1 e 2) e 49,2\% responderam satisfatoriamente (grupo 3). Este resultado aponta a necessidade do aprofundamento deste aspecto. Mais uma vez devido a abstração do fenômeno, a combinação de atividades de simulação e experimentais podem ser uma alternativa.

A relação entre energia e frequência do fóton emitido ou absorvido durante transição foi, aparentemente, bem compreendida, uma vez que 50,8\% dos estudantes apresentaram respostas bem articuladas (pertencentes aos grupos 1 e 2) para a quinta questão e 16,4\% apresentaram respostas satisfatórias (pertencentes ao grupo 3). Entretanto, a análise mostra que aspectos relacionados as transições intermediárias precisam ser discutidos mais atentamente.

No que diz respeito ao uso das simulações, optamos pelo seu emprego como recurso de caráter expositivo e restrito ao professor. Mesmo nestas condições, observamos que o seu emprego exigiu o reconhecimento prévio das funcionalidades, limitações e opções de configuração disponíveis em cada simulação empregada. Desse modo, notamos que ao optar pelo emprego destes recursos diretamente pelos estudantes implicaria necessariamente em reservar algum momento dentro da sequência didática especificamente destinado a ensiná-los como operar com estas ferramentas. Além disso deve-se atentar para a quantidade de computadores compatível com a quantidade de estudantes, hardwares capazes de executar as simulações e disponi- 
bilidade de softwares adicionais exigidos para cada tipo de simulação. Assim, o uso de simulações requer que seja feita uma averiguação técnica nos equipamentos a serem utilizados, caso o professor opte por este caminho. Durante a aplicação da sequência os estudantes apresentaram certas dificuldades na compreensão, não apenas do funcionamento, mas também da representatividade dos objetos da simulação e seus comportamentos, fato este que nos obrigou a desmembrar a última aula da sequência didática em dois encontros, dado a grande quantidade de questionamentos dos estudantes referentes a simulação do átomo de hidrogênio. Tendo feito estas considerações pretendemos, em uma segunda aplicação da SD, testar o uso das simulações pelos estudantes pelo emprego da simulação do átomo de hidrogênio e um roteiro de atividades previamente elaborado para este fim, associando-o com uma atividade experimental referente à espectroscopia.

Também é relevante observar que a diversidade das abordagens utilizadas aparentemente motivou os estudantes a buscar o entendimento do fenômeno por trás da formação das linhas espectrais. Este fato também poderá, em trabalhos futuros, ser investigado através dos áudios coletados durante as aulas, bem como das questões elaboradas pelos estudantes em algumas das atividades propostas ao longo da SD. Consideramos, portanto, que a análise aqui apresentada permite afirmar que a SD apresentou resultados satisfatórios.

\section{Referências}

BASSO, A. C. O átomo de Bohr em nível médio: uma análise sobre o referencial lakatosiano. 2004. 198 f. Dissertação (Mestrado) - Programa de Pós-Graduação Ensino Científico e Tecnológico, Universidade Federal de Santa Catarina, Florianópolis.

BOHR, N. I. On the constitution of atoms and molecules. Philosophical Magazine Series 6, London, v. 26, n. 151, p.1-26, jul. 1913.

BRASIL. Ministério da Educação e Cultura. Secretaria da Educação Básica. Diretrizes Curriculares Nacionais para a Educação Básica. Brasília, 2013.

BRASIL. Ministério da Educação e Cultura. Secretaria da Educação Básica. Orientações Curriculares para o Ensino Médio. Brasília, 2006.

BRASIL. Ministério da Educação e Cultura. Secretaria da Educação Básica. Parâmetros Curriculares Nacionais para o Ensino Médio: Ciências da Natureza e Matemática. Brasília, 2000.

CAVAlCANTE, M. A.; TAVOLARO, C. R. C.; HAAG, R. Experiências em Física Moderna. Física na escola, São Paulo, v. 6, n. 1, p. 75-82, mai. 2005.

FILGUEIRAS, C. A. L. A espectroscopia e a química: da descoberta de novos elementos ao limiar da teria quântica. Química nova na escola, São Paulo, v. 3, p. 22-25, mai. 1996. 
FLICK, U. Desenho da pesquisa qualitativa. Porto Alegre: Artmed, 2009.

IVANJEK, L. et al. Research as a guide for curriculum development: An exemple from introductory spectroscopy. I. Identifying students difficulties with atomic emisson spectra. American Journal Physics, Melville, v. 83, n. 1, p. 85-90, jan. 2015 a.

IVANJEK, L. et al. Research as a guide for curriculum development: An exemple from introductory spectroscopy. I. Addressing student difficulties with atomic emission spectra. American Journal Physics, Melville, v. 83, n. 2, p.171-178, fev. 2015b.

LOPES, C. V. M.; MARTINS, R. A. J. J. Thomson e o uso de analogias para explicar os modelos atômicos: o "pudim de passas" nos livros textos. In: ENCONTRO NACIONAL DE PESQUISA EM ENSINO DE CIÊNCIAS, VII, 2009, Florianópolis. Atas... Belo Horizonte: ABRAPEC. Disponível em: <http://posgrad.fae.ufmg.br/posgrad/viienpec/pdfs/1682.pdf>. Acesso em: 20 ago. 2016.

MCKAGAN, S. B.; PERKINS, K. K.; WIEMAN, C. E. Why we should teach the Bohr model and how to teach it effectively. Physical Review Special Topics: Physics Education Research, Washington, v. 4, n. 010103, p.1-10, mar. 2008.

MEDEIROS, A.; MEDEIROS, C. F. Possibilidades e Limitações das Simulações Computacionais no Ensino de Física. Revista Brasileira de Ensino de Física, São Paulo, v. 24, n. 2, p. 77-86, 02 jun. 2002.

NIAZ, M. et al. Reconstruction of the history of the photoelectric effect and its implications for general physics textbooks. Science Education, [s.1.], v. 94, n. 5, p. 903-931, 14 jan. 2010. Wiley-Blackwell. Disponível em: <http://dx.doi.org/10.1002/sce.20389>.

OLIVEIRA, F. F. de; VIANNA, D. M.; GERBASSI, R. S. Física moderna no ensino médio: o que dizem os professores. Revista Brasileira de Ensino de Física, São Paulo, v. 29, n. 3, p. 447-454, jul. 2007.

PEDUZZI, L. O, Q.; BASSO, A. C. Para o ensino do átomo de Bohr em nível médio. Revista Brasileira de Ensino de Física, São Paulo, v. 27, n. 4, p. 545-557, out. 2005.

PEREIRA, A. P.; OSTERMANN, F. Sobre o ensino de Física Moderna e Contemporânea: uma revisão da produção acadêmica recente. Investigações em Ensino de Ciências, Porto Alegre, v. 14, n. 3, p. 393-420, dez. 2009.

PINHEIRO, L. A.; COSTA, S. S. C.; MOREIRA, M. A. Do átomo grego ao Modelo Padrão: os indivisíveis de hoje. 2012. v. 22, n. 6. Disponível em:

$<$ http://www.if.ufrgs.br/public/tapf/v22_v6_pinheiro_costa_moreira.pdf>. Acesso em: 04 ago. 2016. 
REZENDE JR, M. F.; CRUZ, F. F. S. Física Moderna e Contemporânea na formação de licenciados em Física: necessidades, conflitos e perspectivas. Ciência e Educação, São Paulo, v. 15, n. 2, p. 305-321, 2009.

RUTHERFORD, E. The scattering of $\alpha$ and $\beta$ particles by matter and the structure of the atom. Philosophical Magazine Series 6, London, v. 21, p. 669-688, may. 1911.

SILVA, H. R. A.; MORAES, A. G. O estudo da espectroscopia no ensino médio através de uma abordagem histórico-filosófica: possibilidade de interseção entre as disciplinas de Química e Física. Caderno Brasileiro de Ensino de Física, Florianópolis, v. 32, n. 2, p. 378-406, ago. 2015.

SILVA, A. C.; ALMEIDA, M. J. P. M. Física Quântica no Ensino Médio: o que dizem as pesquisas. Caderno Brasileiro de Ensino de Física, Florianópolis, v. 28, n. 3, p. 624-652, dez. 2011.

STUDART, N. A invenção do conceito de quantum de energia segundo Planck. Revista Brasileira de Ensino de Física, São Paulo, v. 22, n. 4, p. 523-535, dez. 2000.

TERRAZZAN, E. A. A inserção da física moderna e contemporânea no ensino de Física da escola do $2^{\circ}$ grau. Caderno Catarinense de Ensino de Física, Florianópolis, v. 9, n. 3, p. 209 214, dez. 1992.

THOMSON, J. J. On the structure of the Atom: an investigation of the stability and periods of oscillation of a number of corpuscles arranged at equal intervals around the circumference of a circle; with application of the results to the theory of atomic structure. Philosophical Magazine Series 6, London, v. 7, n. 39, p. 237-265, mar. 1904.

WIEMAN, C. E.; PERKINS, K. K.; ADAMS, W. K. Oersted Medal Lecture 2007: Interactive simulations for teaching physics: What works, what doesn't, and why. American Journal Physics: Awards, Melville, v. 76, n. 4, p. 393-399, abr. 2008. 